\title{
Numerical investigation of internal force transfer mechanism in push-out tests
}

\author{
Samy GUEZOULI, Alain LACHAL and Quang-Huy NGUYEN \\ National Institute of Applied Sciences (INSA) - Rennes - France \\ LGCGM - Structural Engineering Research Group \\ Samy.guezouli@insa-rennes.fr \\ Alain.lachal@gmail.com \\ Quang-huy.nguyen@insa-rennes.fr
}

\begin{abstract}
The case of a push-out test specimen made of prefabricated slabs connected by means of grouped headed studs is investigated in this study. In order to analyse the behaviour of such a shear connection, an experimental study and a numerical analysis have been developed. This paper deals with the presentation of numerical results linked to the parametric study of several layout and loading conditions. The specific 2D nonlinear finite element model developed by two first authors has been presented in a previous paper. This specific finite element model has been developed in order to avoid convergence problems that sometimes occur with the introduction of contact-friction elements in 3D models. In addition, this simplified 2D model allows reducing considerably the time computation when the model concerns the study of a structure at real scale. This 2D nonlinear model is supposed to approach the 3D problem using a "zone-equivalence" methodology which we briefly recall the theoretical background. Material nonlinear constitutive laws, 4-noded plane elements and frictional contact finite elements were introduced in the model at the steel concrete interface between the girder flange and the concrete slab and between the studs and the filling concrete. Numerical simulations concerned by this work lead to highlight the internal force transfer mechanisms through the specimen for several layouts and loading conditions, such as the stud arrangements, the filling concrete performance, the reinforcement percentage of the slab, the restrain slab conditions and especially the combination of axial and shear loads. These results could be helpful to have a better interpretation of the push-out test measurements in accordance with the specimen arrangement and the test procedure.
\end{abstract}

\section{Key words}

Contact - Friction - 2D/3D F.E. - Group of studs - Push-out test - Composite structures.

\section{INTRODUCTION}

Beside experimental approaches, numerical studies were undertaken to provide an alternative to push-out tests and to allow a better understanding of the transfer mechanism of internal forces in a push-out specimen. Many searchers have developed 3D FE numerical models these last years but sometimes with a limited success due to the complexity of the numerical modelling of a push-out test. First 3D numerical studies started fifteen years ago with the analysis of push-out specimens with perfobond rib connectors using ANSYS FE program [1]. Ten years ago, Kim et al. [2] have developed 2D and 3D FE models using LUSAS FE program to study the behaviour of through-deck welded shear connectors. The separation 
between the stud and the concrete on the surface of the stud shank opposite to the load was experimentally observed by Johnson and Oehlers [3] and by Jayas [4]. They showed that this phenomenon occurs at low load level and was simulated by giving zero stiffness to the coincident concrete elements with this stud shank surface. Nevertheless, no contact-friction elements were used because the calculation including contact finite elements in a complex 3D FE model such as the push-out test - at both contacts between the steel flange and the concrete slab on one hand and between the studs and the concrete on second hand - appears difficult to converge. First practical design recommendations on the push-out test were undertaken in Europe by Lebet [5], Roik and Hanswille [6]. Few years later, other extensive studies were carried out in Japan ([7], [8]), and in Europe ([9], [10] and [11]). A better interpretation of the push-out test measurements in accordance with the specimen conditioning and the test procedure requires the development of a numerical model that takes into account the complex interaction occurring at different interfaces. We have taken the option to develop a 2D FE model with efficient frictional-contact algorithm. This work constitutes a logical continuity to the first investigation presented in Guezouli and Lachal [12]. It is shown that this model is able to highlight some key phenomena occurring at the interface during a push-test. In this reference, it was concluded that the condensation of a 3-D problem to 2-D seems to work very well compared to experimental test results provided that the friction coefficients are numerically adjusted. Recently, Qureshi et al. [13], studied the effect of shear connector spacing and layout on the shear connector capacity in composite beams. The proposed 3D model (Plan dimensions: $1500 \mathrm{~mm} \times 1500 \mathrm{~mm}$ ), is loaded as a horizontal push test. This model developed with ABAQUS, includes a profiled sheeting and the interfaces concerned by the contact algorithm are: (top profile sheeting - bottom of the concrete slab) and (shaft of the headed studs - surrounding concrete). Friction coefficient is equal to 0.5 for the first contact interface (unfortunately, the authors did not give the value for the second interface). The comparison between F.E. analysis and push test experiments is reasonably well especially prior the maximum of the shear resistance of the stud. The Authors did not give information about time computation and convergence conditions. Nevertheless, this work appears very interesting for this particular composite beam.

The proposed study aims to give to researchers and engineers a better knowledge concerning the shear force transfer mechanism throughout the specimen during the standard push-out test. The interest of the numerical investigation is focused on the influence of some parameters (such as the arrangement of the studs, the influence of the filling reinforced concrete performance and different loading and boundary conditions) on the percentage of shear force supported by the studs on one hand and by friction on second hand. The numerical results aim to help the searchers and engineers to avoid special test conditions that could lead to a misinterpretation of the experimental results.

\section{SIMPLIFIED 2D F.E. MODEL}

\section{1 "Zone-equivalence" methodology}

The truly 3D problem (Figures 1, 2 and 3 ) is reduced to a 2D equivalent plane stress model using a "Zone-equivalence" methodology. The main objective is to approach the 3D stress field by an equivalent in-plane stress state which enables us to better understand the internal force transfer mechanisms in push-out tests. This model reduces the out-of-plane dimension of each material of the specimen to equivalent materials of $1 \mathrm{~mm}$. The procedure takes into account the extent of each material encountered in this direction and relies on homogenization principles. The transformation preserves the overall stiffness and strength of each component of the specimen. In XY plan, the specimen is divided into five zones A, B, C, D and E (Figure $1)$. 
- For the zone A, only the thickness of the web $\left(Z_{A}=t_{w}\right)$ is reduced to $1 \mathrm{~mm}$.

- For the zone $B$, the width of the flange $\left(Z_{B}=b_{f}\right)$ is reduced to $1 \mathrm{~mm}$.

- For the zone $C$, a width of $\left(Z_{C}=\right.$ slab width $)$ reinforced slab is firstly homogenized into an equivalent slab concrete and then it is reduced to $1 \mathrm{~mm}$.

- For the zone $\mathrm{D}$, a width of $\left(2 \mathrm{Z}_{\mathrm{D} 1}\right)$ reinforced slab is firstly homogenized into an equivalent filling concrete and a width of $\left(Z_{D_{2}}\right)$ reinforced filling concrete into an equivalent filling concrete as well. Obtained equivalent width of filling concrete material is then reduced to $1 \mathrm{~mm}$ thickness.

- For the zone E, the same homogenization than the zone D is carried out with adding the three studs in Z-direction (total stud-width: $3 \times \mathrm{d}_{2}$ ) and taking care to reduce the width of the filling concrete from $\left(\mathrm{Z}_{\mathrm{D} 2}\right)$ to $\left(\mathrm{Z}_{\mathrm{D} 2}-3 \times \mathrm{d}_{2}\right)$. Obtained material in this case is an equivalent stud-material. Its width is also at least reduced to $1 \mathrm{~mm}$ thickness.

Looking into $\mathrm{X}$-direction, the zone $\mathrm{E}$ is stopped at the top of the head-studs; it remains only the continuity of zones $\mathrm{C}$ and $\mathrm{D}$.
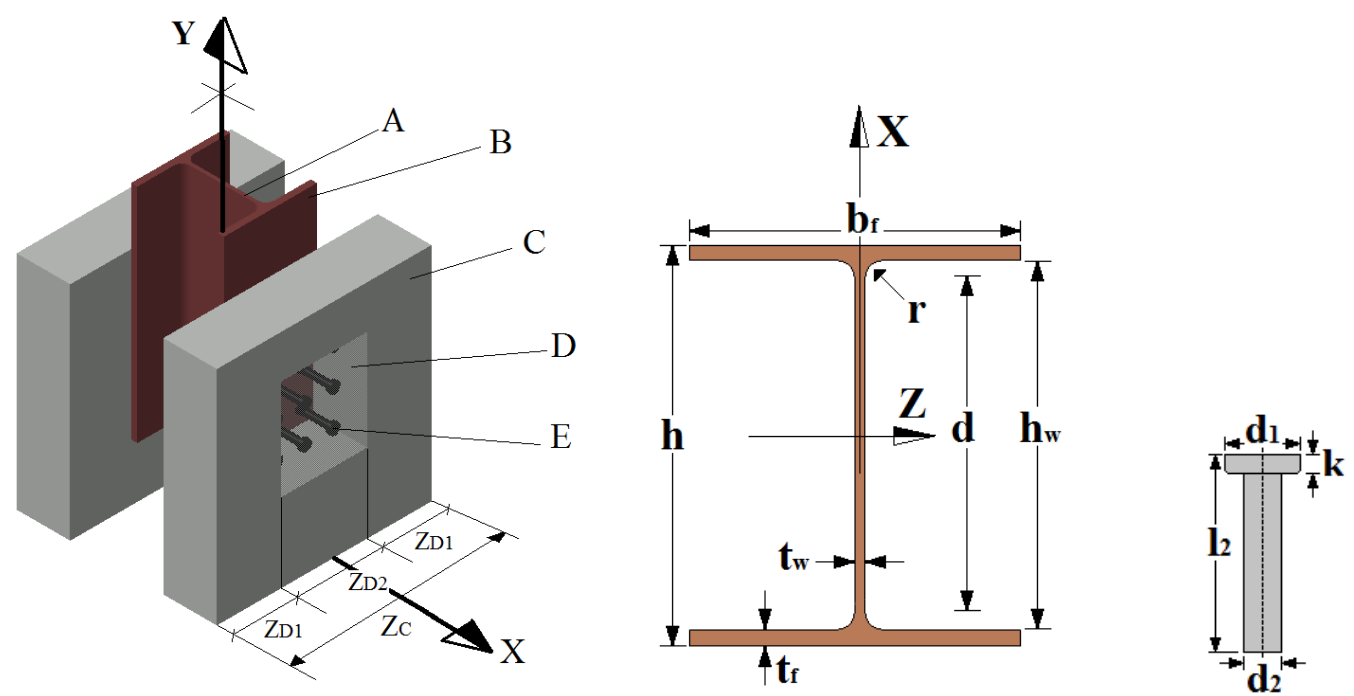

Figure 1. Push-out test specimen. Figure 2. HEB260 cross-section. Figure 3. The stud.

The equivalent 2D model and the real 3D specimen should have the same deformation. This means that the mechanical behaviours should be adapted. While the Young's moduli have been changed as shown in table 1, the yield stresses (in tension as well as in compression) should be multiplied by appropriate value of ( $\sum \bar{Z}$ : each cell of column 2 in Table 1$)$ that depends on the concerned zone along $\mathrm{Z}$ axis. Figure 4 shows how to adapt the model behaviour of each material from truly 3D model to the equivalent 2D model. Reinforcing steel (Young's modulus $\mathrm{E}_{\mathrm{s}}$ ) representing $1 \%$ of the concrete volume appears through the homogenization so; the concrete original widths are firstly modified by homogenization as follows:

$$
\mathrm{Z}_{\mathrm{i}}=\mathrm{Z}_{\mathrm{i}}^{\text {original }}\left[0.99+0.01 \frac{\mathrm{E}_{\mathrm{s}}}{\mathrm{E}_{\mathrm{cm}}}\right]_{\mathrm{i}=1,2,3}
$$

In table 1, are noted:

WG: web-girder, FG: flange-girder, SC: concrete-slab, FC: filling-concrete and ST: studs.

Table 1. Equivalent Young's moduli. 


\begin{tabular}{|c|c|c|c|}
\hline Zones & $\begin{array}{l}\text { Material } \\
\text { thicknesses } \\
\text { included }\end{array}$ & $\begin{array}{l}\text { E calculation (/1mm) and total equivalent width } \\
\qquad \sum \overline{\mathrm{Z}}\end{array}$ & $\begin{array}{l}\text { Homogenized } \\
\text { material }\end{array}$ \\
\hline $\mathrm{A}$ & $\mathrm{t}_{\mathrm{w}}$ of WG & $\mathrm{E}^{(\mathrm{WG})} \times \mathrm{t}_{\mathrm{w}}$ & Web girder \\
\hline B & $b_{f}$ of FG & $\mathrm{E}^{(\mathrm{FG})} \times \mathrm{b}_{\mathrm{f}}$ & Flange girder \\
\hline $\mathrm{C}$ & $\mathrm{Z}_{\mathrm{C}}$ of $\mathrm{SC}$ & $\mathrm{E}_{\mathrm{cm}}^{(\mathrm{SC})} \times \mathrm{Z}_{\mathrm{C}} \quad \sum \overline{\mathrm{Z}}=\mathrm{Z}_{\mathrm{C}}$ & Slab concrete \\
\hline $\mathrm{D}$ & $\begin{array}{l}2 Z_{\mathrm{D} 1} \text { of } \mathrm{SC} \\
+\mathrm{Z}_{\mathrm{D} 2} \text { of } \mathrm{FC}\end{array}$ & $\begin{array}{c}\mathrm{E}_{\mathrm{cm}}^{(\mathrm{FC})} \times\left(\mathrm{n}_{\mathrm{eq}}^{(\mathrm{SC} \rightarrow \mathrm{FC})} \times 2 \mathrm{Z}_{\mathrm{D} 1}+\mathrm{Z}_{\mathrm{D} 2}\right) \\
\sum \overline{\mathrm{Z}}=\mathrm{n}_{\mathrm{eq}}^{(\mathrm{SC} \rightarrow \mathrm{FC})} \times 2 \mathrm{Z}_{\mathrm{D} 1}+\mathrm{Z}_{\mathrm{D} 2} \\
\mathrm{n}_{\mathrm{eq}}^{(\mathrm{SC} \rightarrow \mathrm{FC})}=\frac{\mathrm{E}_{\mathrm{cm}}^{(\mathrm{SC})}}{\mathrm{E}_{\mathrm{cm}}^{(\mathrm{FC})}}\end{array}$ & $\begin{array}{l}\text { Filling } \\
\text { concrete }\end{array}$ \\
\hline $\mathrm{E}$ & $\begin{array}{c}2 \mathrm{Z}_{\mathrm{D} 1} \text { of } \mathrm{SC} \\
+\left(\mathrm{Z}_{\mathrm{D} 2}-3 \mathrm{~d}_{2}\right) \\
\text { of } \mathrm{FC} \\
+3 \mathrm{~d}_{2} \text { of } \mathrm{ST}\end{array}$ & $\begin{array}{c}\mathrm{E}^{(\mathrm{ST})} \times\left(\mathrm{n}_{\mathrm{eq}}^{(\mathrm{SC} \rightarrow \mathrm{ST})} \times 2 \mathrm{Z}_{\mathrm{D} 1}+\mathrm{n}_{\mathrm{eq}}^{(\mathrm{FC} \rightarrow \mathrm{ST})} \times\left(\mathrm{Z}_{\mathrm{D} 2}-3 \mathrm{~d}_{2}\right)+3 \mathrm{~d}_{2}\right) \\
\sum \overline{\mathrm{Z}}=\mathrm{n}_{\mathrm{eq}}^{(\mathrm{SC} \rightarrow \mathrm{ST})} \times 2 \mathrm{Z}_{\mathrm{D} 1}+\mathrm{n}_{\mathrm{eq}}^{(\mathrm{FC} \rightarrow \mathrm{ST})} \times\left(\mathrm{Z}_{\mathrm{D} 2}-3 \mathrm{~d}_{2}\right)+3 \mathrm{~d}_{2} \\
\mathrm{n}_{\mathrm{eq}}^{(\mathrm{SC} \rightarrow \mathrm{ST})}=\frac{\mathrm{E}_{\mathrm{cm}}^{(\mathrm{SC})}}{\mathrm{E}^{(\mathrm{ST})}} \text { and } \mathrm{n}_{\mathrm{eq}}^{(\mathrm{FC} \rightarrow \mathrm{ST})}=\frac{\mathrm{E}_{\mathrm{cm}}^{(\mathrm{FC})}}{\mathrm{E}^{(\mathrm{ST})}}\end{array}$ & Stud \\
\hline
\end{tabular}

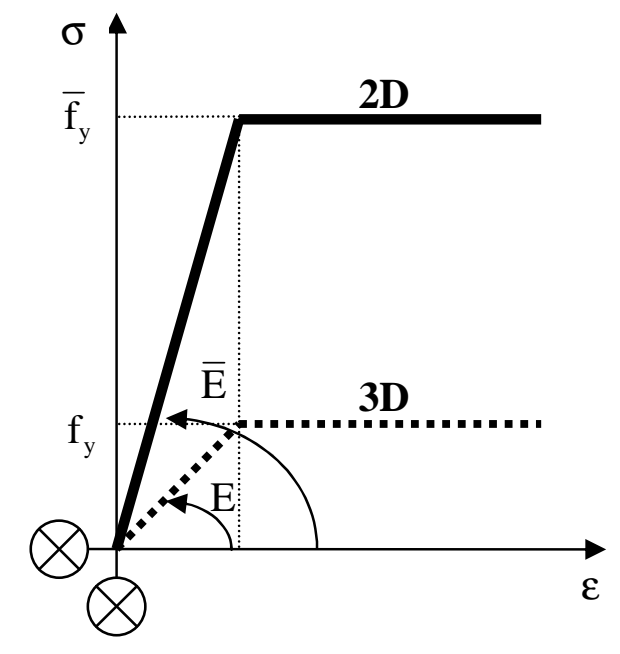

(a) - Girder and stud.

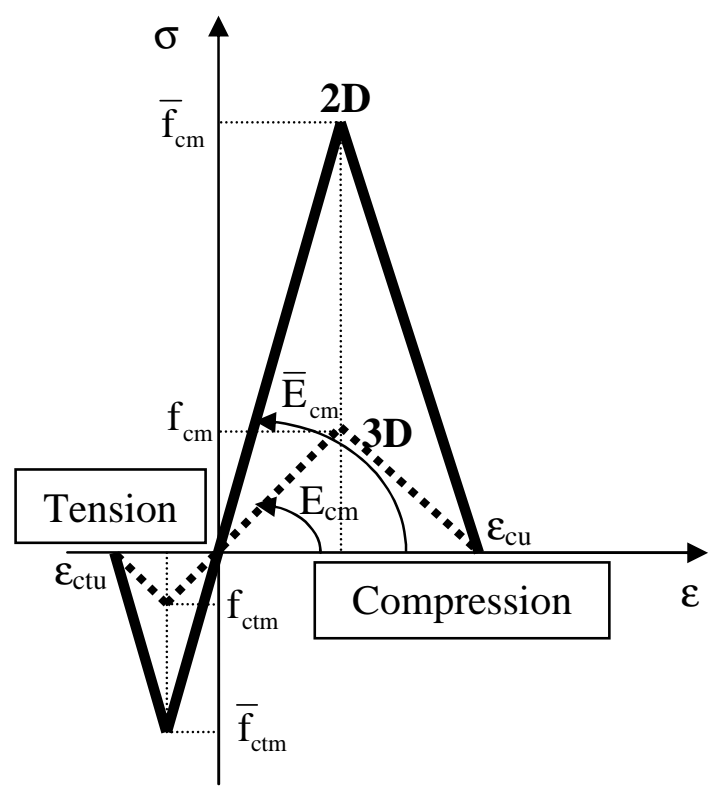

(b) - Concrete.

Figure 4. 2D-3D equivalent material behaviours.

\subsection{F.E. model}

Taking advantage of the symmetry of the specimen, only a half of the push-out specimen was modelled with 4-noded F.E.. The calculation is performed in plane stress. Contact friction elements were modelled by two lines of nodes (Figure 5). The penalty method is used defining master and slave elements. For different contact interfaces, the steel is considered as master and the concrete as slave. The contact is unilateral (without penetration). The frictional behaviour is described using Coulomb model which involves the friction coefficient $\mu$. In accordance with Figure 5, the contact formulation is described below:

- Contact without penetration condition: 


$$
\left(U_{n} \geq 0 \text { and } N \geq 0\right) \Rightarrow U_{n} N=0
$$

- Friction condition:

$$
\left(U_{t}>0 \Rightarrow-\vec{T}=\mu \vec{D}\right) \text { or } \quad\left(U_{t}=0 \Rightarrow-\vec{T}<\mu \vec{D}\right)
$$

where: $\mu=\frac{T}{N}$ is the friction coefficient and $\vec{D}=\frac{\vec{U}_{t}}{\left|\vec{U}_{t}\right|}$.

In practice, two lines of nodes must be created from two different materials. These lines must be as close as possible that makes the contact between the closer front-nodes. This precaution ensures good convergence of the iterative process.

The friction coefficient is different between the flange and the concrete $\left(\mu_{1}\right)$ and between the studs and the concrete $\left(\mu_{2}\right)$. These constant values have been adjusted in a previous investigation (Guezouli and Lachal [12]).

It is pointed out that the FE model does not take into account the possible stud failure for a high value of vertical displacement. The maximum vertical displacement is limited to $8 \mathrm{~mm}$ (slightly more the maximum slip of the stud that is about $6 \mathrm{~mm}$ ).

The stresses and strains obtained with the 2D proposed model should have a post-processing treatment. Real values are those corresponding to the truly 3D problem. The inverted procedure is applied to each zone of the $2 \mathrm{D}$ model dividing the values by $\sum \overline{\mathrm{B}}$ (each cell of column 2 in Table 1).

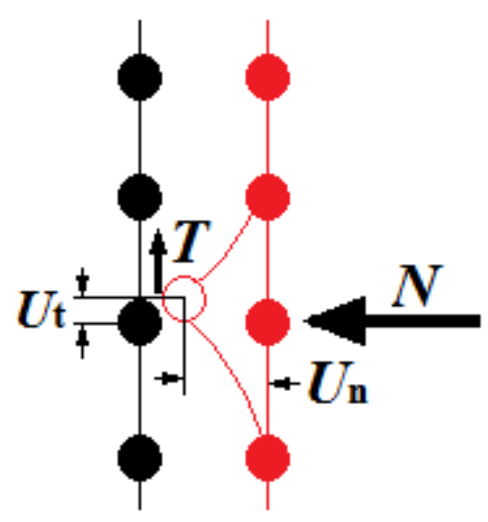

Figure 5. Contact variables.

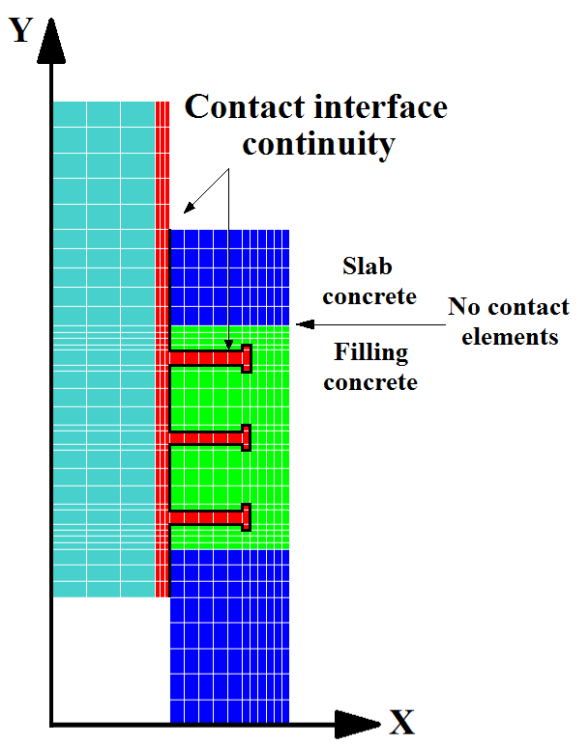

Figure 6. Contact interfaces.

In addition, Johnson and Oehlers [3] observed experimentally a separation between the studs and the concrete on the surface of the stud shank opposite to the load. While contact surfaces are continuous (Figure 6), the model should be able to simulate this phenomenon. A perfect continuity between the filling and slab concretes is supposed, no contact interface is needed. The contact between the support and the concrete base of the specimen could have an influence on the global behaviour. In the beginning of this investigation, the support contact is 
supposed free in X-direction and no contact F.E. are needed (standard push-out test). When the contact-friction is considered at this interface, the support should be meshed and added to the F.E. model with an appropriate friction coefficient. Different boundary and loading conditions will be tested below in a parametric study.

\subsection{Calibration against experimental results}

The particular type of push-out test specimen investigated in this work was designed according to the recommendations given in EN 1994-1-1 - Annexe B [14]. It includes one HEB 260 (S 355) steel section with a beam length of $750 \mathrm{~mm}$. The geometrical characteristics of the profile cross-section: web (A) and flanges (B), are given in Figure 7 and Table 2. Two prefabricated slabs $(620 \mathrm{~mm}$ high, $600 \mathrm{~mm}$ wide, $150 \mathrm{~mm}$ thick) are symmetrically arranged on each side of the steel beam. Each slab includes a double reinforcement layer with $2 \times 4 \phi 10$ mm longitudinal rebars of $550 \mathrm{~mm}$ length and $2 \times 5 \phi 10 \mathrm{~mm}$ transversal rebars of $520 \mathrm{~mm}$ length both in steel grade $S 500\left(f_{y}=500 \mathrm{~N} / \mathrm{mm}^{2}, f_{u}=550 \mathrm{~N} / \mathrm{mm}^{2}, E_{s}=210000 \mathrm{~N} / \mathrm{mm}^{2}\right)$. The two prefabricated slabs (C) are connected to the steel girder flanges by means of 9 welded headed studs (E) (Table 2) grouped inside a rectangular $(240 \times 280 \mathrm{~mm})$ recess. The filling material used to achieve the connection had the same composition as the concrete C40/50 of the prefabricated slab, i.e. Cement CPA, CEMI, 0/14 TP: $405 \mathrm{~kg} / \mathrm{m}^{3}$, Aggregates 6,3/14: 966 $\mathrm{kg} / \mathrm{m}^{3}$, Sand 0/4: $834 \mathrm{~kg} / \mathrm{m}^{3}$, Admixtures: $1.62 \mathrm{~kg} / \mathrm{m}^{3}$, Water: $189 \mathrm{~kg} / \mathrm{m}^{3}$. The mean value of the compressive strength of the concrete slab and filling materials, obtained from cylinder tests, is $56 \mathrm{MPa}$. For the numerical investigation, this specimen (3 horizontal rows of 3 studs each with a vertical distance between horizontal rows of studs equal to $4.26 \mathrm{~d}_{2}$ and same slab and filling concrete will be called "standard specimen"). The proposed $2 \mathrm{D}$ model validation (Figure 8) has been undertaken comparing numerical and experimental results of exactly the same push-out test conditions of the present work. This comparison gave satisfactory results and has proven the performance of this $2 \mathrm{D}$ simplified model calibrated with a couple of friction coefficients: $\mu_{1}=0.2$ and $\mu_{2}=0.3$.
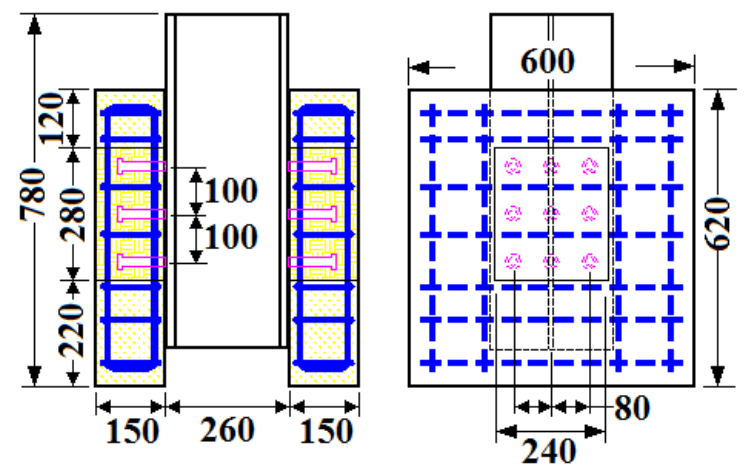

Figure 7. Geometry of the specimen $(\mathrm{mm})$.

Table 2. Geometrical characteristics of HEB260 and stud ( $\phi 19)$.

\begin{tabular}{|c|c|c|c|c|c|c|c|c|c|c|c|}
\hline Variable & $\mathrm{h}_{\mathrm{w}}$ & $\mathrm{t}_{\mathrm{w}}$ & $\mathrm{b}_{\mathrm{f}}$ & $\mathrm{t}_{\mathrm{f}}$ & $\mathrm{H}$ & $\mathrm{d}$ & $\mathrm{r}$ & $\mathrm{d}_{2}$ & $\mathrm{l}_{2}$ & $\mathrm{~d}_{1}$ & $\mathrm{k}$ \\
\hline Value $(\mathrm{mm})$ & 225 & 10 & 260 & 17.5 & 260 & 177 & 24 & 19 & 100 & 31.7 & 10 \\
\hline
\end{tabular}




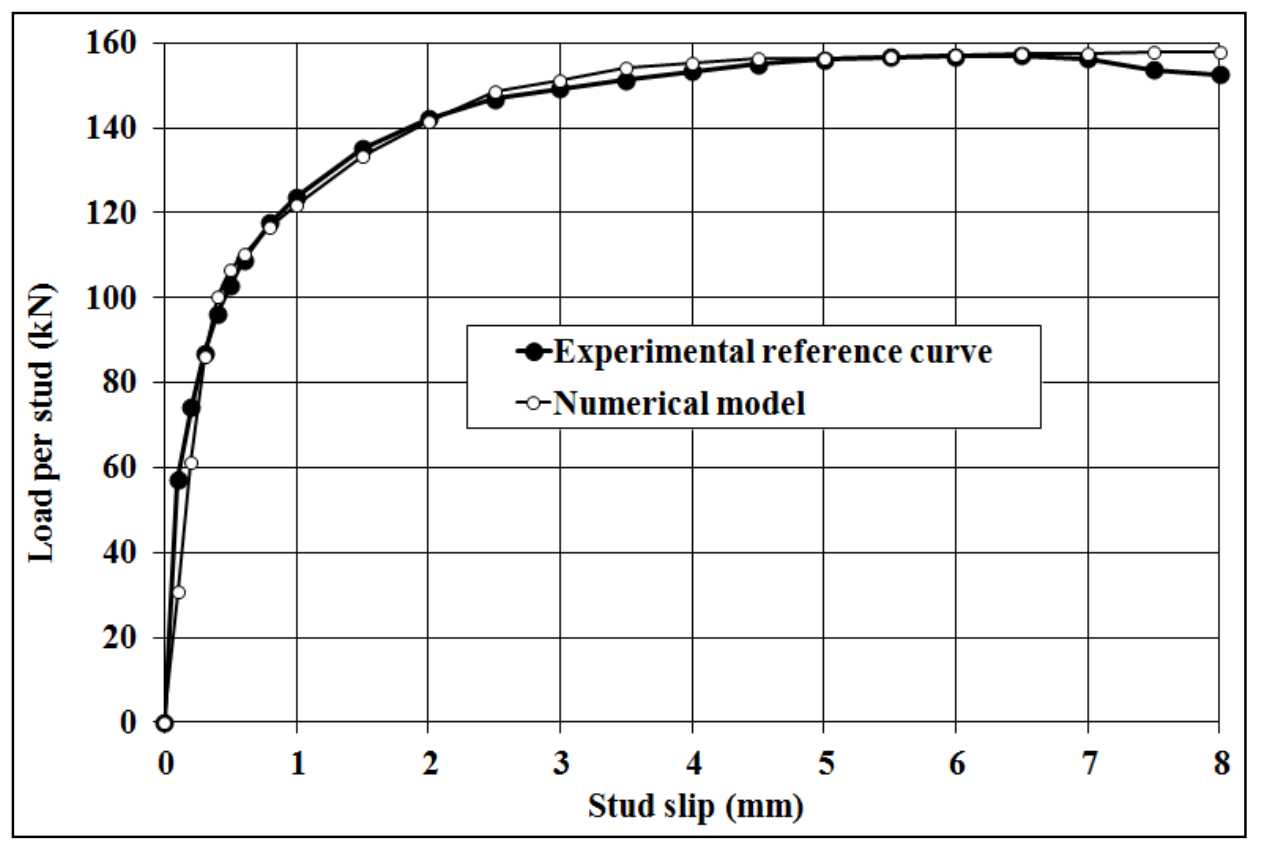

Figure 8. 2D model validation (Guezouli and Lachal [12]).

\section{ANALYSIS METHOD}

In Figure 9.a, (source: Nelson stud welding Inc.), following weld zones can be distinguished:

A: Heat-unaffected stud material,

B: Stud heat affected zone (HAZ),

C: Cast zone,

D: Base material HAZ,

E: Heat-unaffected base material.

When performed properly, the stud weld is stronger than both the stud material and base plate material. The failure will occur at the ultimate steel strength in the stud shank or in the base plate, rather than in the weld. This reality justifies the simplified modelling of this detail while the finite element model developed in this work (Figure 9.b) does not include the modelling of the weld fillet.

Concerning the numerical model, the cross-section $A B$ in Figure 9.b separates the stud from the flange. If the stud is considered as an isolated system, the shear force on $A B$ belongs to the stud and it belongs to the flange if the flange is the isolated system. These forces are calculated using the stress field in the concerned finite elements of each material. While contact finite elements are used between the concrete covering the stud and the stud on one hand, and continuously between this concrete and the flange on second hand, it appears easy to compare the magnitude of the shear force (parallel to $A B$ ) supported by the stud and the one supported by the flange. These shear forces could have same magnitude if there is no concrete covering the stud.

In reality, this investigation will show that the effort in the flange is greater than the one in the stud due to the concrete covering the stud especially in a quasi-pure shear loading procedure like a push-out test. The effort of the stud is in reality overestimated and the use of the wellknown formulae of the stud resistance $P_{R d}(E q .4 . b)$ to design the stud appears conservative (case where Eq. 4.b is less than Eq. 4.a). 


$$
P_{R d}=\operatorname{Min}\left\{\begin{array}{l}
(a)-\text { Resistance of the concrete covering the stud : } 0.29 \alpha d^{2} \sqrt{f_{c k} E_{c}} / \gamma_{v} \\
(b)-\text { Resistance of the stud : } 0.8 f_{u} \frac{\pi d^{2}}{4 \gamma_{v}}
\end{array}\right.
$$

$f_{c k}$ and $E_{c}$ : concrete mechanical properties,

$f_{u}$ : shear resistance of stud material (450 to $\left.500 \mathrm{MPa}\right)$,

$d$ : stud diameter,

$\alpha$. factor takes into account the height of the stud,

$\gamma_{v}$ : safety factor (1.25 at ultimate limit state - it is the inverse of 0.8 ).

However, the effort calculated with the model at the cross-section $A B$ and considering the stud as an isolated system remains interesting even if it is not in practice the one used to design it; it is interesting because it helps to understand the shear force transfer mechanism and the margin of resistance that Eq. $4 . b$ can provide during the design of the studs in push-out test.

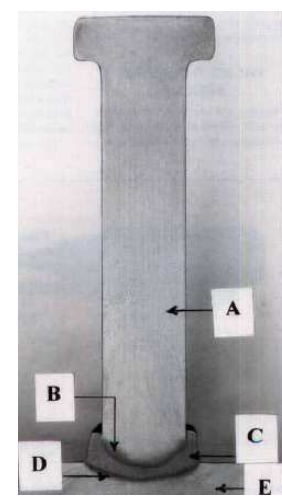

Figure 9.a Welded stud.

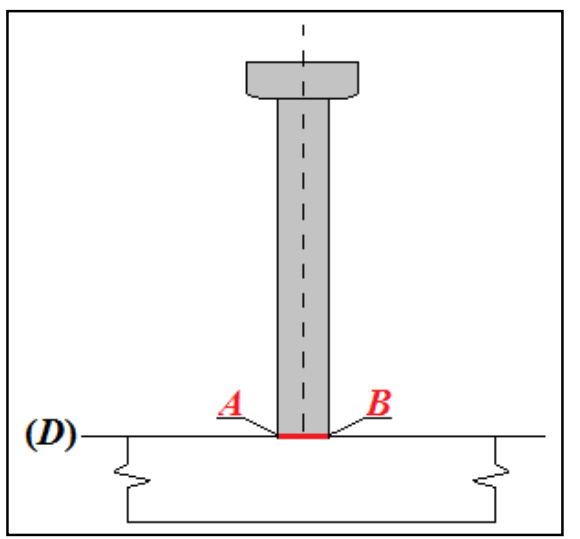

Figure 9.b Cross-section $A B$.

Before beginning the study of the influence of various parameters on the transfer mechanism of the shear force during a push-out test, the force transfer mechanism from the applied load at the top of the steel section to the reaction at the support of the concrete panel should be well-understood; consequently, an analysis method is developed. This analysis must consider separately both cases with or without friction. The specimen is loaded by imposed displacement at the top of the steel section $(0$ to $8 \mathrm{~mm})$; the inverted function gives the corresponding loads that give easily the resultant. The example concerned by Figure 10 (case without friction: $\mu_{1}=\mu_{2}=0$ ) and Figure 11 (case with friction: $\mu_{1}=0.2$ and $\mu_{2}=0.3$ ) corresponds to the first step loading of the specimen $(0.1 \mathrm{~mm})$. Whatever the case, the vertical equilibrium should be satisfied: the applied load should be equal to the reaction at the base of the specimen.

- If the steel section is isolated from the whole specimen, the common nodes between the steel section flange and the studs give the magnitude of the force transmitted through these nodes.

Force transmitted by the steel section through the common nodes $=\sum W$

In the case without friction: $\mid$ Applied load $\mid=\sum W$

In the case with friction: $\mid$ Applied load $\mid>\sum W$ 
- If the studs are isolated from the whole specimen, the absolute values of the forces at the precedent common nodes (noted $V$ ) are different than $W$ because they include those coming from the steel section and those coming from the reactions of the concrete on the studs. In this configuration, it appears that the force transmitted by the steel section through the common nodes to the rest of the specimen is partially absorbed by the studs as a shear force on one hand and the rest directly by concrete contact as reaction on the studs, on second hand. This appears at the bottom common node of each stud-row subjected to a concrete reaction (and not at the top node). In table 3, concerning top stud-row of Figure 10, the efforts coming from the flange, transmitted to the studs and supported (as a reaction) by the concrete are detailed.

Table 3. Shear force transmitted by the top row of studs.

\begin{tabular}{|c|c|c|}
\hline Flange & Studs & Concrete reaction on studs \\
\hline Top node & Top node & Top node \\
$47884 N$ & $-47884 N$ & $47884 N-47884 N=0 N$ \\
\hline Bottom node & Bottom node & Bottom node \\
$21799 N$ & $5461 N$ & $21799 N+5461 \mathrm{~N}=27260 \mathrm{~N}$ \\
\hline
\end{tabular}

The vertical equilibrium is always satisfied for each stud-row ( $V=E$ in absolute values) that gives $(\Sigma V=\Sigma E)$.

Shear force transmitted by the base section of the studs $=\sum V$

- If the concrete panel is isolated from the whole specimen, it is easy to recover the applied load coming from the steel section. The filling concrete in contact with the studs gives following reactions:

- At the contact nodes of the stud base, a part of this reaction is $\left(\sum R_{b}=\sum W+\sum V\right.$ in algebraic values).

- At the rest of contact nodes around the stud, the sum of reactions is easily calculated.

The sum of both parts of reaction on the studs verifies the equilibrium with the force transmitted by the steel section through the common nodes $(\Sigma W)$.

The reaction $R$ at the base of the specimen is calculated by the sum of forces at each node of the concrete support. For the case without friction (Figure 10), the force transmitted by the steel section through the common nodes $(\Sigma W)$ is equal to the applied load and also equal to the reaction $R$ but appears greater than the real shear force supported by the studs $(2 V)$ due to the reaction at the base of the studs. For the case with friction (Figure 11), the force transmitted by the steel section through the common nodes $(\Sigma W)$ is different of the applied load and consequently different of the reaction $R$. It appears greater than the shear force supported by the studs $(\Sigma V)$ due to the reaction at the base of the studs on the one hand and to the friction on the second hand. The effort absorbed by friction remains always equal to:

$$
F=\sum W-R
$$

Considering the forces in absolute values, the results of this investigation can be summarized as follows:

- Case without friction: 
Percentage of shear force supported by the studs: $\frac{\sum V}{R} \times 100=\frac{115342}{176162} \times 100=65.5 \%$

Percentage of concrete reaction on studs: $\frac{\sum R_{c}}{R} \times 100=\frac{176162}{176162} \times 100=100 \%$

\section{- Case with friction:}

Percentage of shear force supported by the studs: $\frac{\sum V}{R} \times 100=\frac{106048}{177756} \times 100=59.6 \%$

Percentage of concrete reaction on studs $: \frac{\sum R_{c}}{R} \times 100=\frac{176508}{177756} \times 100=99 \%$

Percentage of friction $: \frac{F}{R} \times 100=\frac{1248}{177756} \times 100=1 \%$

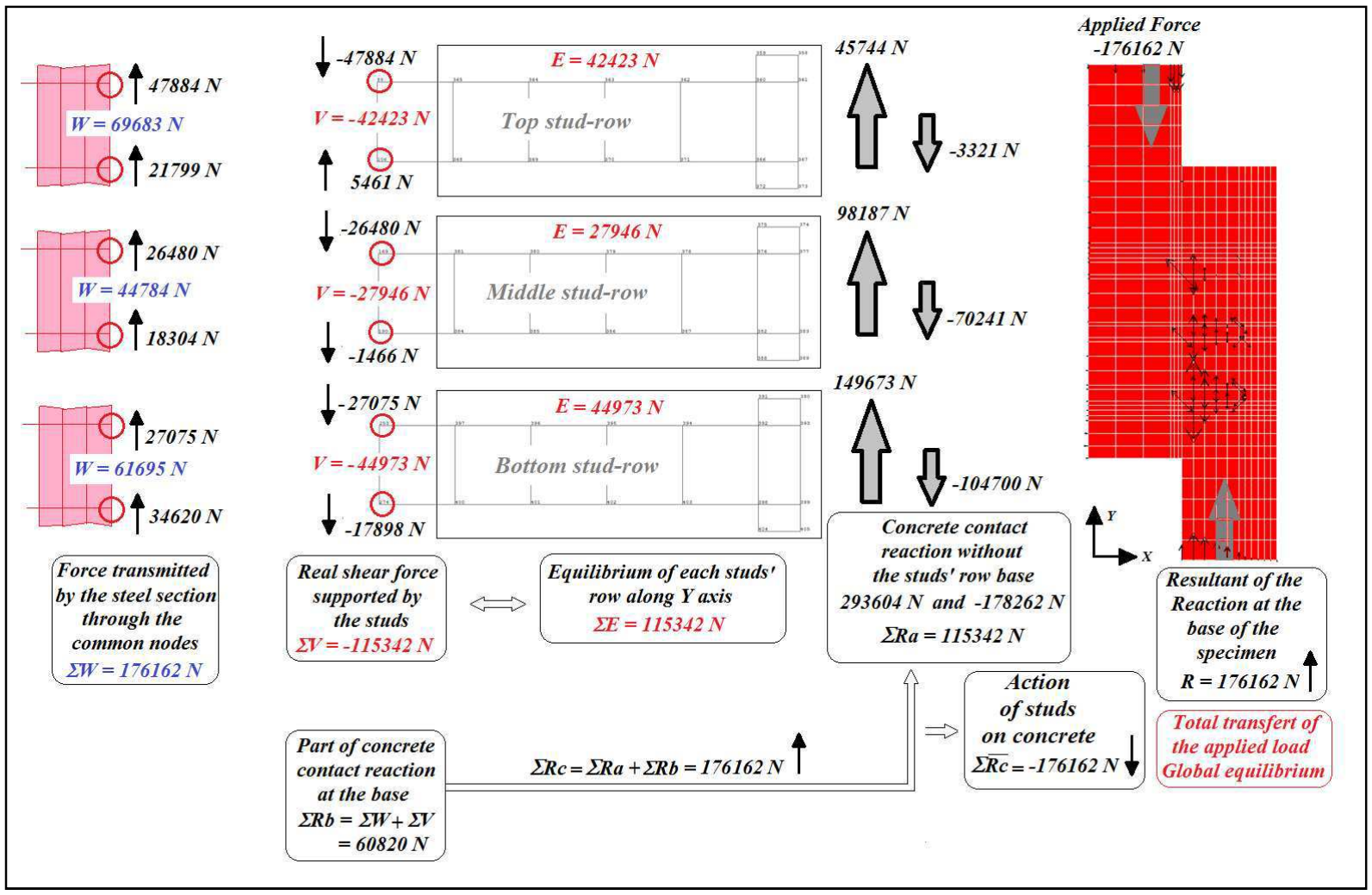

Figure 10 - Force details trough the specimen - Case without friction. 


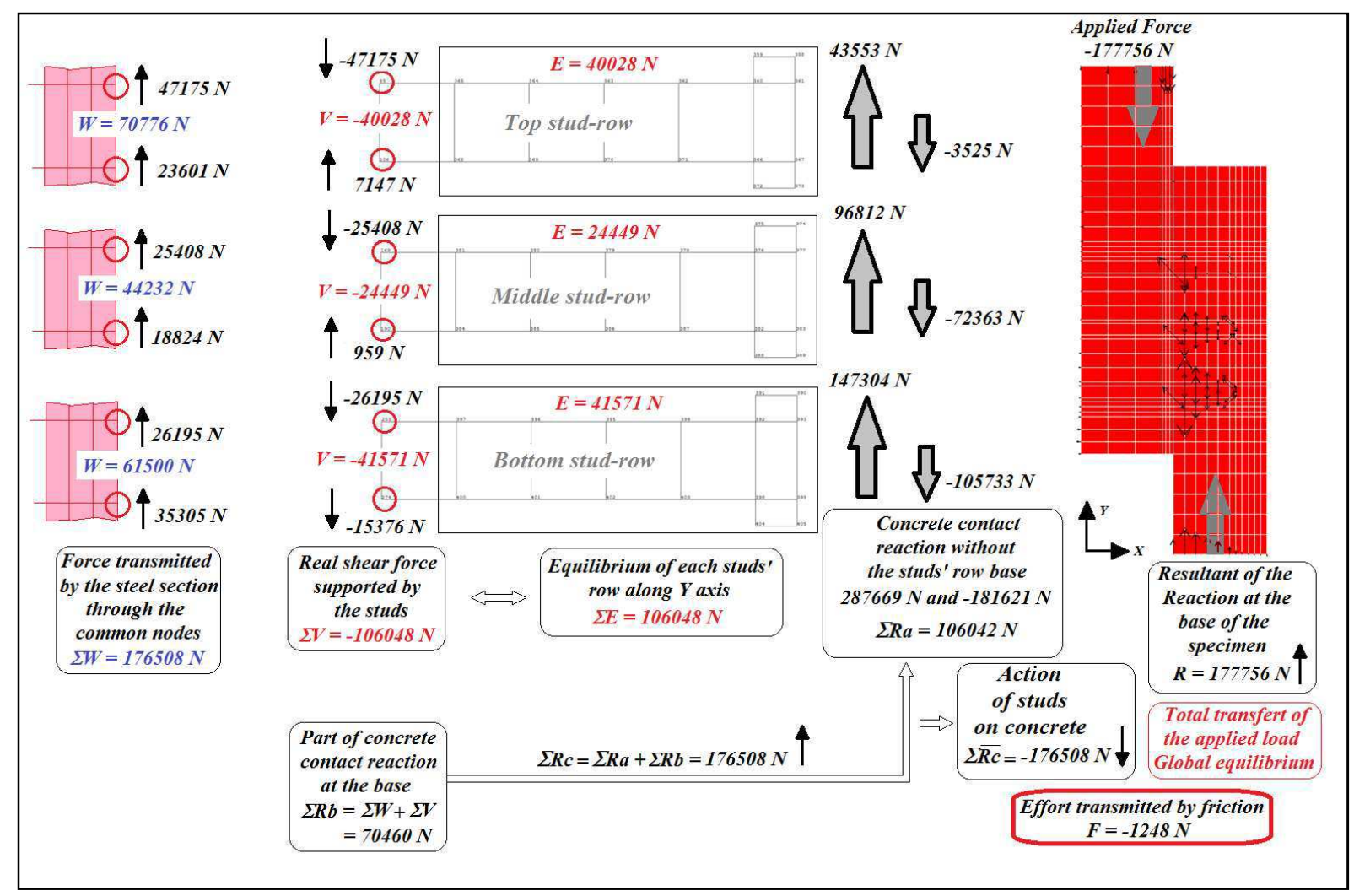

Figure 11 - Force details trough the specimen - Case with friction.

The comparison between both cases gives also:

- Total effort supported by the push-out test in the case without friction: $R=176162 \mathrm{~N}$ becomes in the case with friction: $R=177756 \mathrm{~N}$ (1\% more).

- Total shear force supported by the studs in the case without friction: $2 \mathrm{~V}=115342 \mathrm{~N}$ becomes in the case with friction: $\Sigma V=106048 \mathrm{~N}$ ( $8 \%$ less).

To conclude this investigation, the percentage of the shear force supported by the studs is less than $100 \%$ of the applied load (only $65.5 \%$ in case without friction and $59.6 \%$ in case with friction), this effect is due to the concrete reaction. Generally in practice, the effort assigned to each stud during a standard push-out test is calculated dividing the applied load by the number of studs; this estimate has two important defects: the first one is that the effort is not totally supported by the studs as shown above and the second one is that the effort has not same magnitude between horizontal rows of studs as will be shown through the numerical simulations.

After this investigation, it is possible to get exact shear force supported by the studs as well as exact force due to friction between materials. The study is now focused on the influence of several parameters and different test condition on the part of effort due to friction on the one hand and the part of shear force relevant to each stud-row during a push-out test, on the second hand.

\section{NUMERICAL SIMULATIONS}

For following different numerical simulations, the yield stress of the stud is equal to $529 \mathrm{MPa}$, and considering a diameter equal to $19 \mathrm{~mm}$, it leads to a limit force about: $150 \mathrm{KN}$. The interest is focused on the percentage of shear force supported by each stud compared to the 
one supported by the friction between the concrete and the steel section. These percentages are calculated as follows:

$$
p_{i}^{(s)}(\%)=\frac{V_{i}}{R} \times 100 \text { (for each stud row } i \text { ) and } p^{(f)}(\%)=\frac{F}{R} \times 100 \text { (for friction) (6) }
$$

Where: $V_{i}$ is the part of shear force supported by the stud row " $i$ ", $F$ is the one supported by friction and $R$ is the total reaction.

The remaining percentage difference $\left(100 \%-\sum_{i} p_{i}^{(s)}-p^{(f)}\right)$ is due to the concrete reaction at the base of the studs.

The corresponding curves (force-slip) at each stud are also presented (the force calculated at each horizontal stud-row is divided by 3 that corresponds to the number of studs in $\mathrm{Z}$ direction).

\subsection{Influence of the studs arrangement}

The influence of the number of horizontal rows of studs and their vertical spacing requires a special interest especially for prefabricated slabs connected by grouped headed studs. The filling material used to achieve the connection had the same composition as the concrete $\mathrm{C} 40 / 50$ of the prefabricated slab. The base of the specimen is supposed free in X-direction and the right side of the concrete panel is unloaded (only an imposed vertical displacement is applied at the top of the steel section)

\subsubsection{Influence of the number of horizontal stud-rows}

A first model (Figure 12.a) considers only the middle horizontal row of studs. A second model (Figure 12.b) keeps both top and bottom horizontal rows. A third model (Figure 12.c) includes the three horizontal rows. Boundary and loading conditions are shown also in these figures. For these three cases (Figure 12), the mesh remains the same and the positions of the stud-rows in cases 1 and 2 are the same as in case 3.

In Figures 13.a, b and c, the percentage supported by the friction is low $(<2 \%)$ during the whole loading history. This is due to the free support along $\mathrm{X}$-axis and also to the free rightside of the concrete panel. The vertical displacement causes a fast separation between the steel section flange and the concrete panel. Only a small area remains in frictional contact at the top side of concrete. Concerning the percentage and magnitude of shear force supported by each stud:

- In the Case 1 (Figure 13.a), the percentage of the shear force supported by the stud-row reaches a maximum of $80 \%$ of the applied load. The corresponding force reaches the resistance limit $(150 \mathrm{kN})$ for an imposed vertical displacement equal to $4 \mathrm{~mm}$.

- In the Case 2 (Figure 13.b), each stud-row supports around a maximum of $40 \%$ percentage of shear force. This means that both stud-rows share the amount of the shear force that was supported by only one stud in the Case 1. Corresponding forces reach the resistance limit when the imposed vertical displacement approaches $8 \mathrm{~mm}$.

- In the Case 3 (Figure 13.c), each stud-row supports around a maximum of $24 \%$ percentage of shear force. This means that the stud-rows share also the amount of the shear force that was supported by only one stud-row in the Case 1 . Corresponding forces do not reach the resistance limit before imposed vertical displacement of $8 \mathrm{~mm}$. 
Considering the mesh and the boundary conditions of the model presented in Figure 12 for imposed vertical displacement greater than $2 \mathrm{~mm}$, it can be conclude that the percentage of shear force supported by each stud-row " $i$ " of a specimen with " $n$ " stud-rows is approximately:

$$
p_{i}^{(s)}(\%) \approx \frac{p_{1}^{(s)}(\%)}{n}
$$

where $p_{l}^{(s)}(\%)$ is the percentage of shear force for a specimen with only one stud-row (Case 1) that is around $80 \%$ of the applied load in this example.

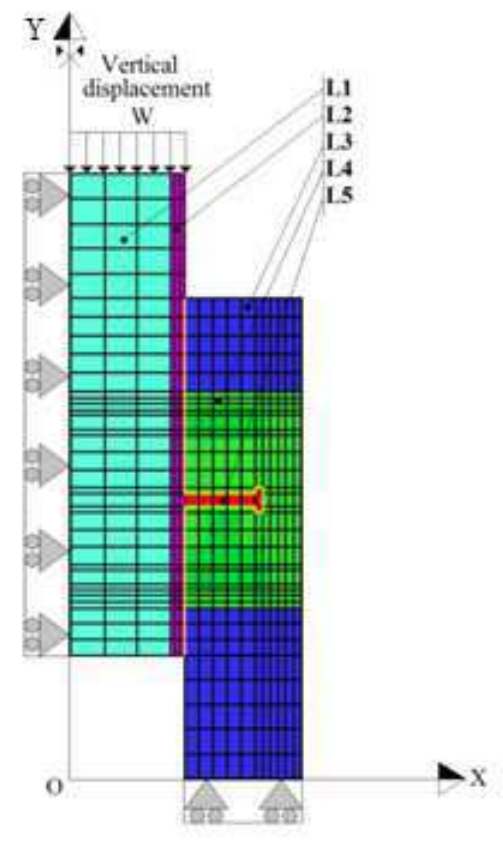

a - Case 1

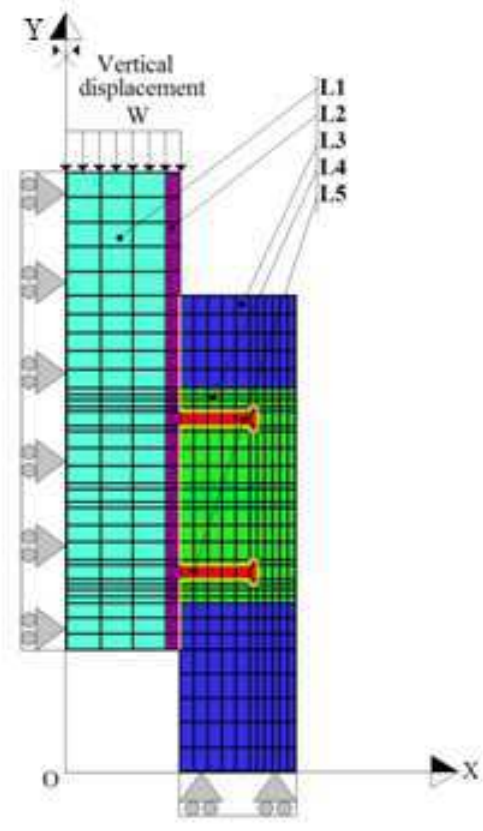

$\mathrm{b}-$ Case 2

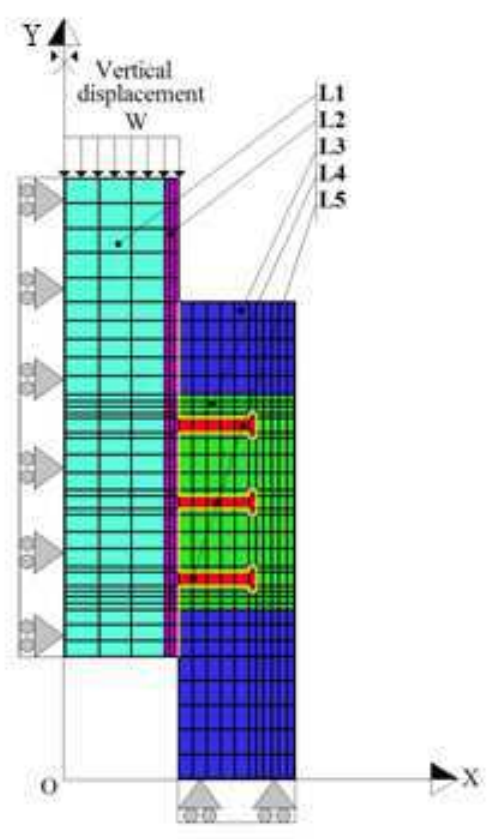

c - Case 3

Figure 12 - Mesh of half-specimen - Boundary conditions - Loading.
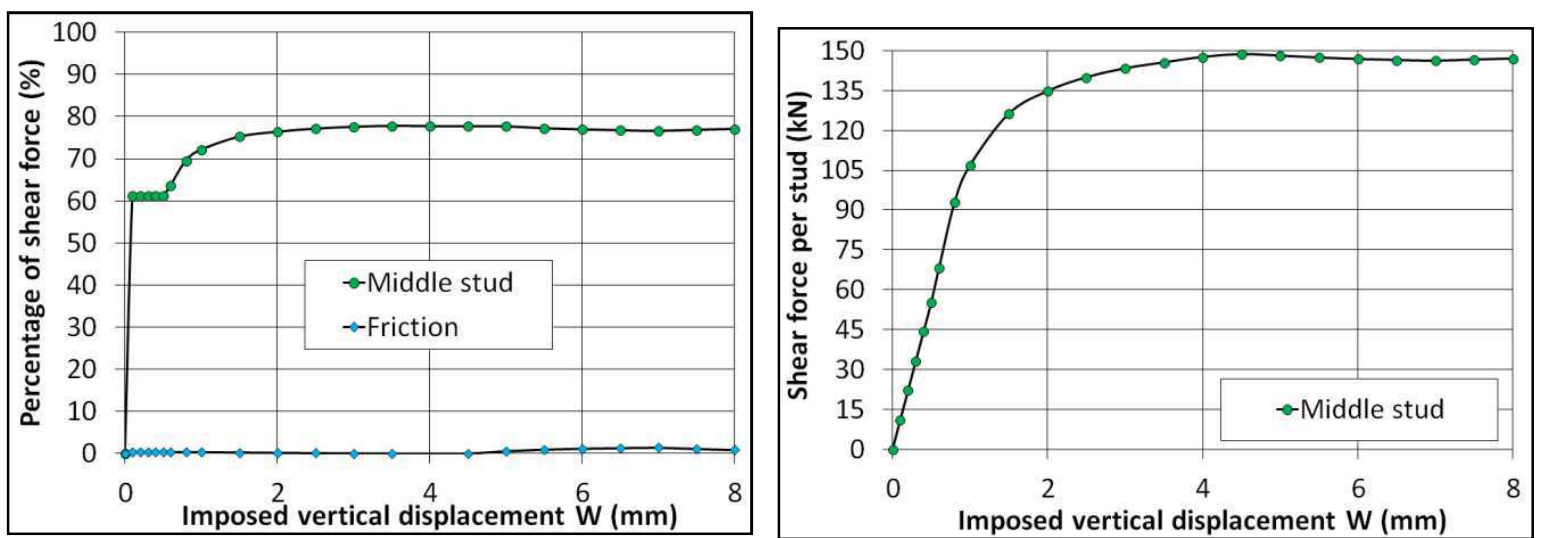

a-Case 1 . 

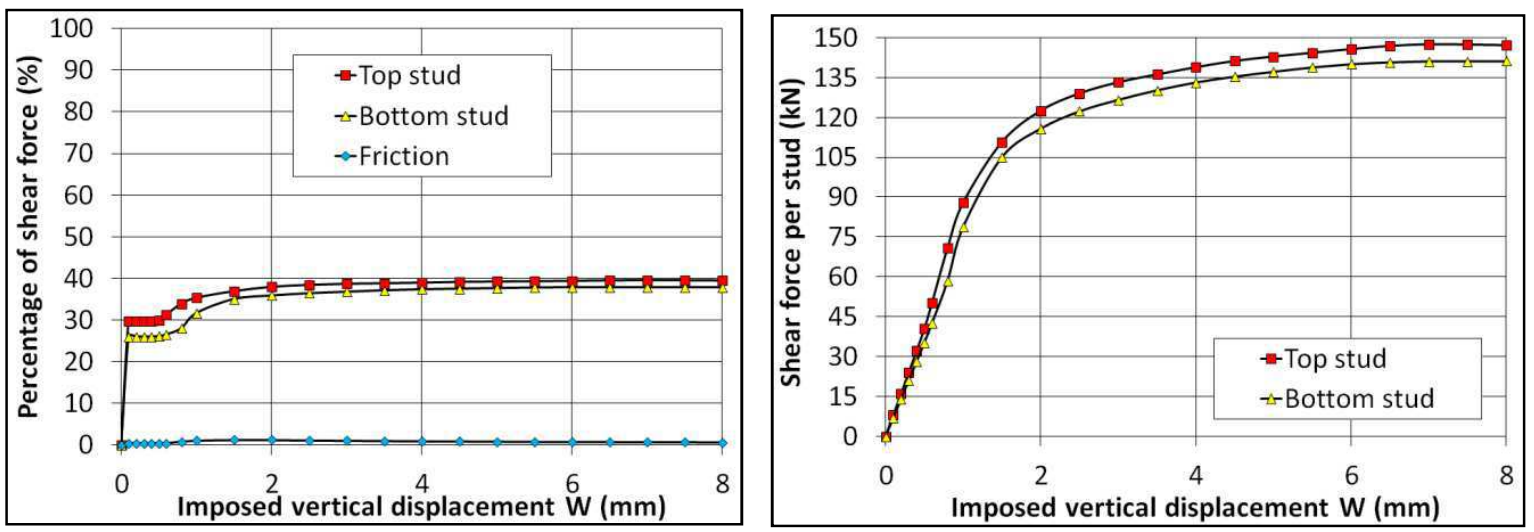

$\mathrm{b}-$ Case 2.
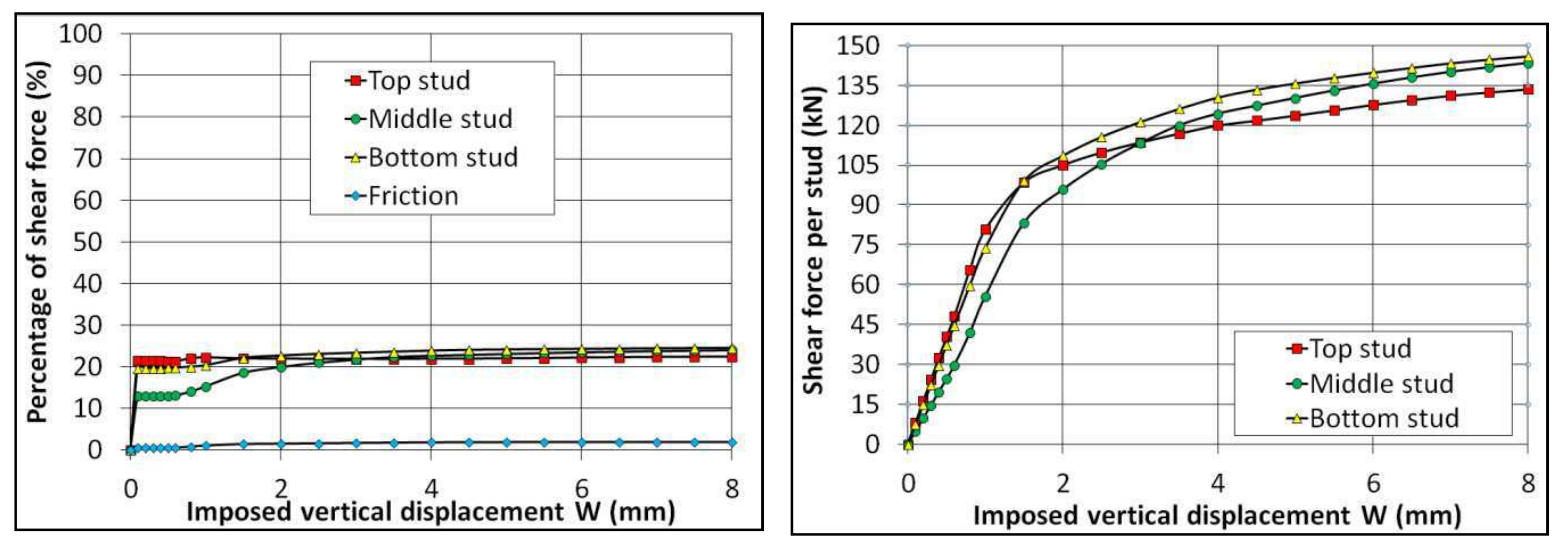

c-Case 3 .

Figure 13 - Percentages and magnitude of shear forces in the studs.

\subsubsection{Influence of the vertical distance between horizontal stud-rows}

To introduce this investigation, it is important to remind that in accordance with Annex B of EC4, and also to clause 6.6.5.7, the minimum spacing is about $5 \times \mathrm{d}_{2}\left(\mathrm{~d}_{2}\right.$ : diameter of the stud). The Case 4 (Figure 14) is closed to this value.

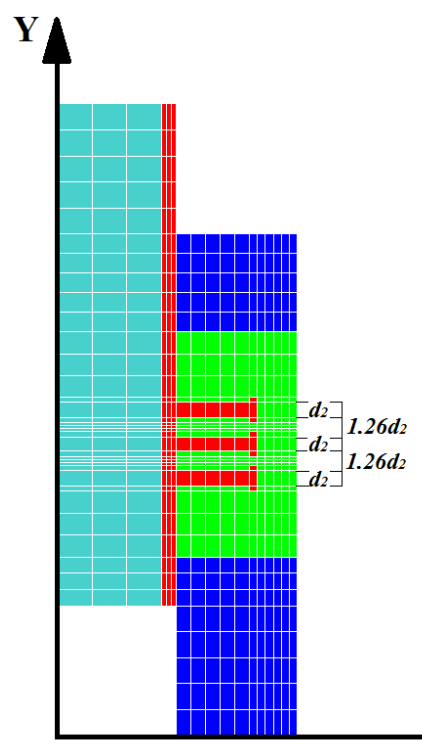

a-Case 1

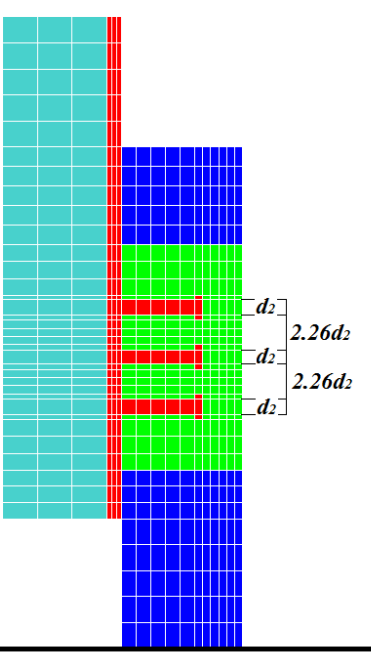

$\mathrm{b}$ - Case 2

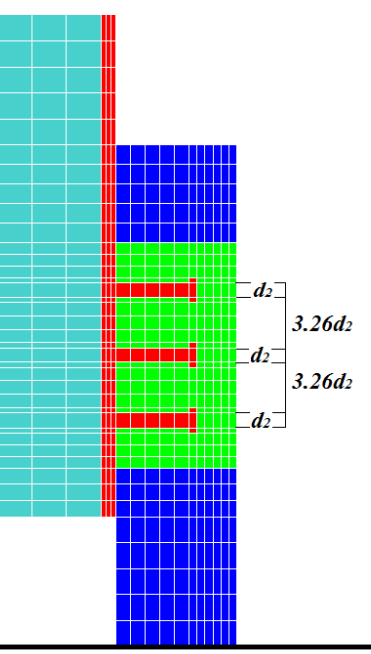

c - Case 3

$(3.26 \mathrm{~d} 2=62 \mathrm{~mm})$

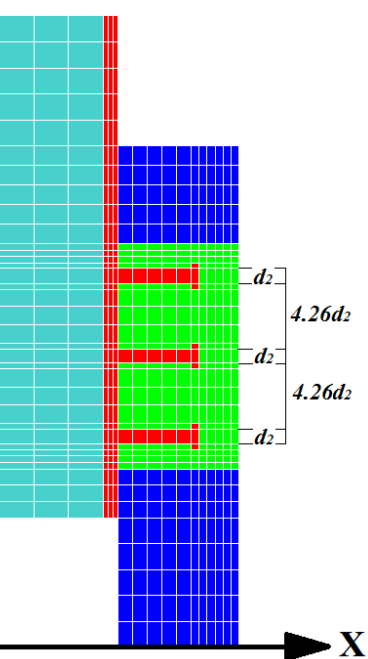

d - Case 4

$(4.26 \mathrm{~d} 2=81 \mathrm{~mm})$

$(2.26 \mathrm{~d} 2=43 \mathrm{~mm})$ 
Figure 14 - Distance between horizontal stud-rows.

In the aim to show that this distance is secure, this investigation proposes to compare it with theoretical lower values (Cases 1 to 3 ).

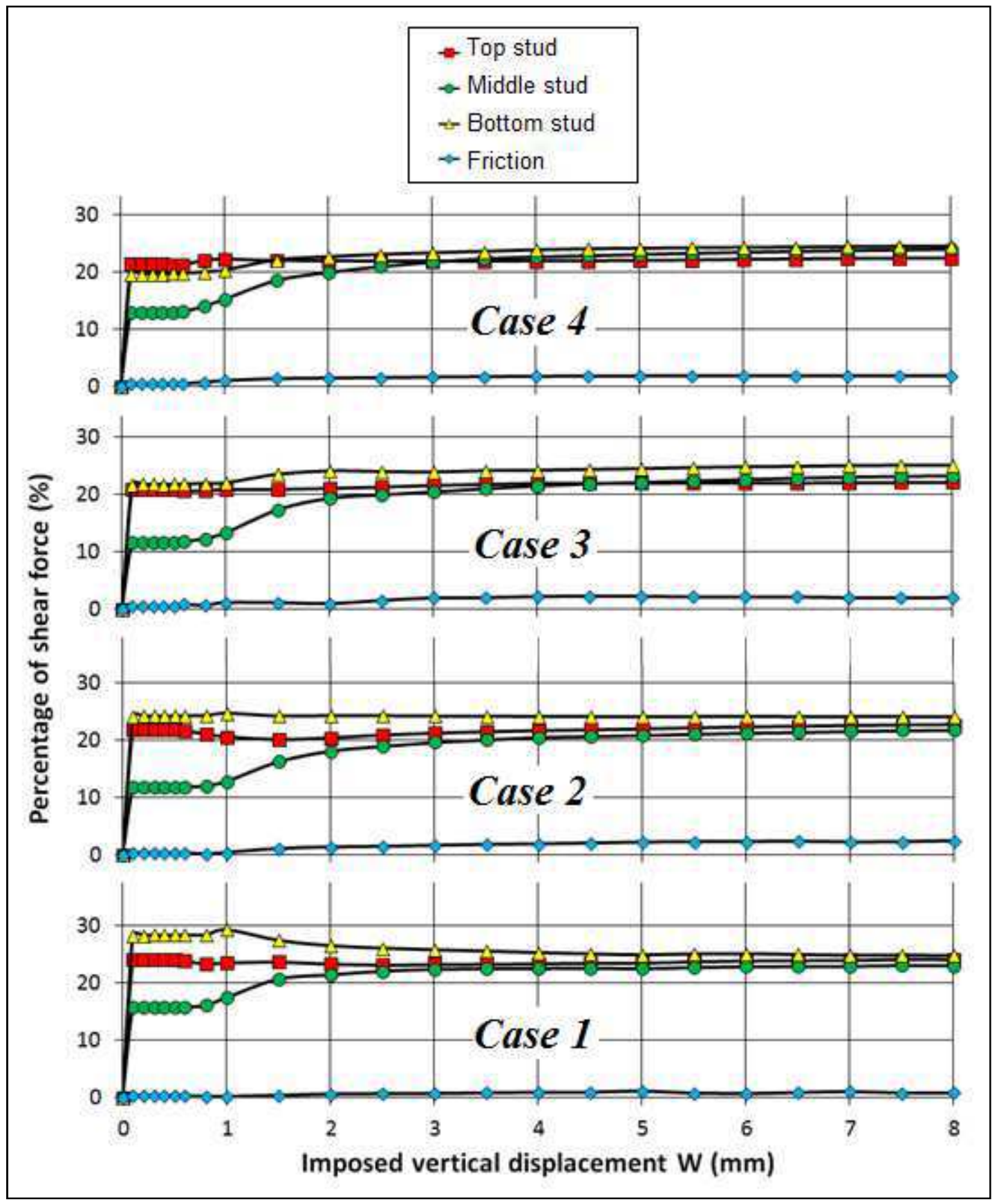

Figure 15 - Percentages of shear forces in the studs. 


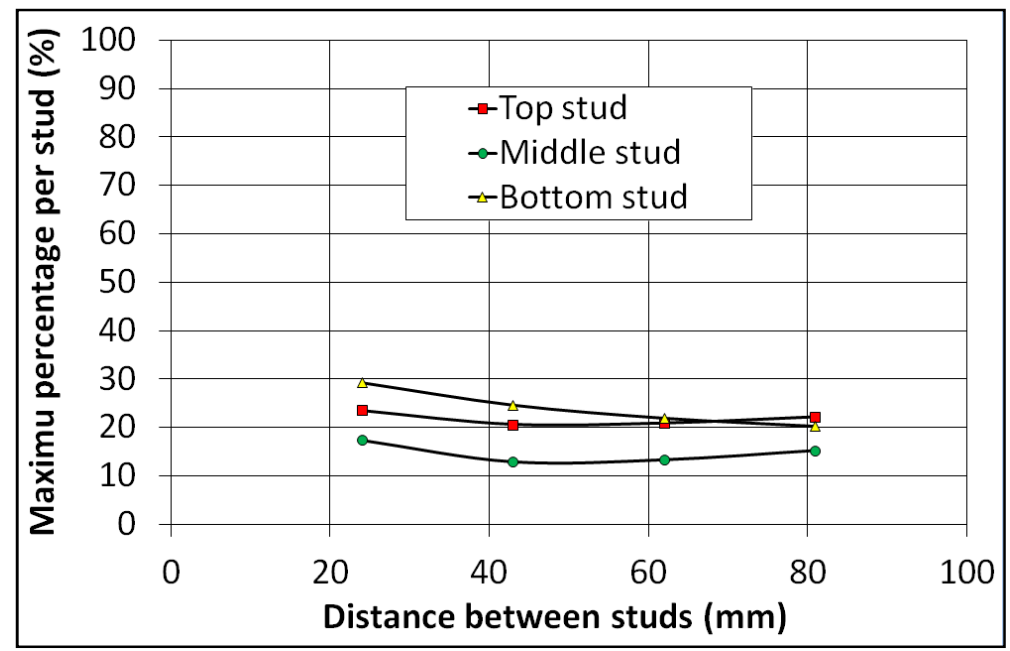

Figure 16 - Shear force percentages $(W=1 \mathrm{~mm})$.

In Figure 15 are plotted the percentages of shear force supported by each stud-row for case 1 to case 4 (see Figure 14). The percentage of shear force supported by friction is also plotted in Figure 15. It appears that, for first imposed vertical displacements (in the range of 0 to $1 \mathrm{~mm}$ ), shear forces supported by stud-rows are greater in Case 1 than in Case 4. This appears clearly in Figure 16 plotted for an imposed vertical displacement $W$ equal to $1 \mathrm{~mm}$. For imposed vertical displacements greater than $1 \mathrm{~mm}$, progressively, the shear force supported by studrows in all cases tends towards a same value of about $23 \%$. The maximum friction percentage remains less than $2 \%$ of the applied load. The friction effect appears more important with the most spaced stud-rows (Case 4). It is worth to point out that with the increase in spacing between the stud-rows, the concrete action becomes increasingly important and the total force supported by the push-out specimen also increases. These results confirm the requirements of Annex B of EC4, and also the clause 6.6.5.7.

\subsection{Influence of the homogenised filling concrete performance}

The proposed model takes into account the reinforcing bars by homogenization as mentioned in section 2. Precedent simulations considered $1 \%$ reinforcing bars of the concrete volume (Eq. 1). The influence of the rebars percentage is similar than the influence of the filling concrete performance. This conclusion is predictable because the homogenisation changes the depths $B_{i}$ (Eq. 1) that is similar to make changes to the resistance of the concrete through the equivalent Young's moduli (Table 1). For this reason, it appears enough to study the influence of the filling concrete performance. The specimen considered herein is the Case 4 (Figure 14). The base of the specimen is supposed free in the X-direction and the right side of the concrete panel is unloaded (only an imposed vertical displacement is applied at the top of the steel section)

The studs are arranged in recesses filled by high performance concrete $(H P C)$ while for the rest of the slab standard-concrete $(S C)$ is used. Nevertheless, in this investigation it could be interesting to know also the lower limit class of the filling concrete that are called $(N P C)$. Table 4 gives different values of characteristic compression stress $f_{c k}$ and corresponding, maximum compression stress $f_{c m}$, maximum tension stress $f_{c t m}$ and secant Young's modulus $E_{c m}$, using following equations:

$$
f_{c m}=1.2 f_{c k} \quad f_{c t m}=0.6+0.06 f_{c m} \quad E_{c m}=22000\left(f_{c m} / 10\right)^{0.3}
$$


The strain $\varepsilon_{m}^{(S C)}=0.0022$, the other values of the strain $\varepsilon_{m}$ are calculated using following equation:

$$
\varepsilon_{m}=\varepsilon_{m}^{(S C)}\left(E_{c m} / E_{c m}^{(S C)}\right)
$$

Table 4. Mechanical characteristics of some normal and high performance concretes.

\begin{tabular}{|c|c|c|c|c|c|c|c|}
\hline Parameters & \multicolumn{9}{|c|}{$\begin{array}{c}\text { Normal Performance Concrete } \\
\text { (NPC) }\end{array}$} & $\begin{array}{c}\text { Slab } \\
\text { standard- } \\
\text { Concrete }\end{array}$ & \multicolumn{3}{|c|}{ High Performance Concrete (HPC) } \\
\hline$f_{c k}(\mathrm{MPa})$ & 30 & 40 & 50 & 56 & 70 & 80 & 90 \\
\hline$f_{c m}(\mathrm{MPa})$ & 36 & 48 & 60 & 67 & 84 & 96 & 108 \\
\hline$f_{c t m}(\mathrm{MPa})$ & 2.8 & 3.5 & 4.2 & 4.6 & 5.6 & 6.4 & 7.1 \\
\hline$E_{c m}(\mathrm{MPa})$ & 32308 & 35220 & 37659 & 38961 & 41659 & 43361 & 44921 \\
\hline$\varepsilon_{m}$ & 0.0020 & 0.0022 & 0.0023 & 0.0024 & 0.0026 & 0.0027 & 0.0028 \\
\hline & $N P C 1$ & $N P C 2$ & $N P C 3$ & $S C$ & $H P C 1$ & $H P C 2$ & $H P C 3$ \\
\hline
\end{tabular}

The shear force supported by each stud-row from lower performance of filling concrete (NPC1) to higher performance (HPC3) versus imposed vertical displacement are plotted in Figure 17. $(S C)$ corresponds to the reference case where the slab concrete and the filling concrete are the same. It appears that more the filling concrete performance increases, more the magnitude of the shear force supported by each stud-row decreases.

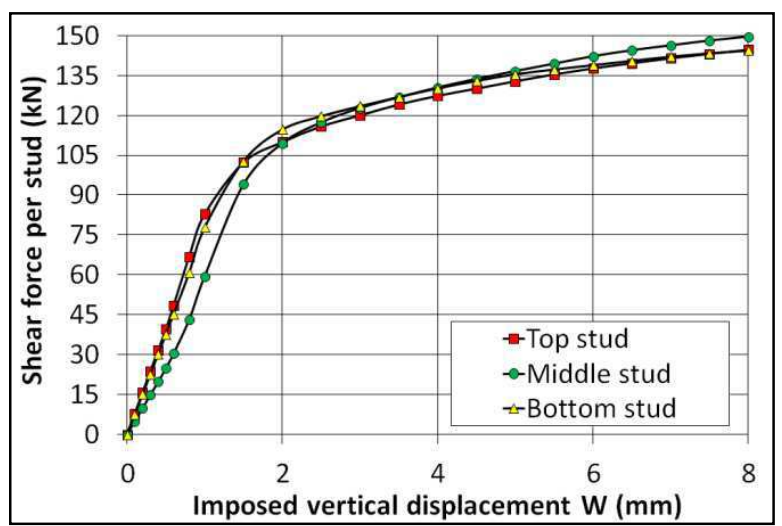

$\mathrm{a}-\mathrm{NPC} 1$.

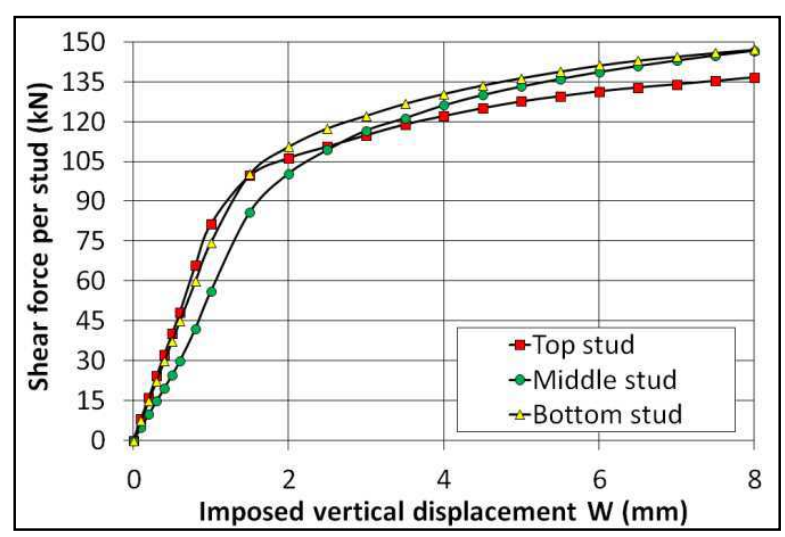

$\mathrm{c}-N P C 3$.

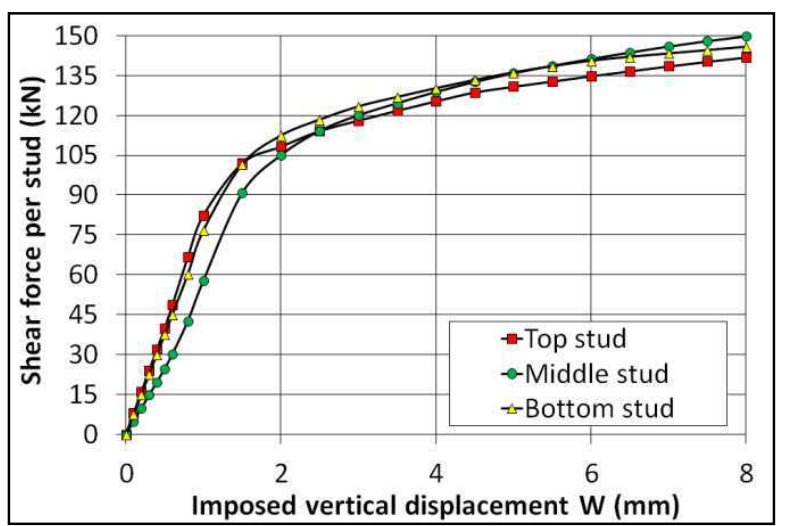

$\mathrm{b}-N P C 2$.

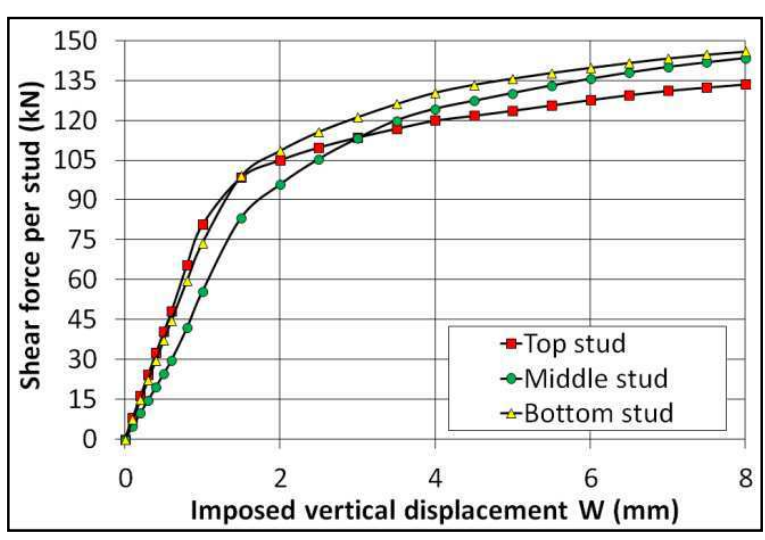

$\mathrm{d}-S C$. 


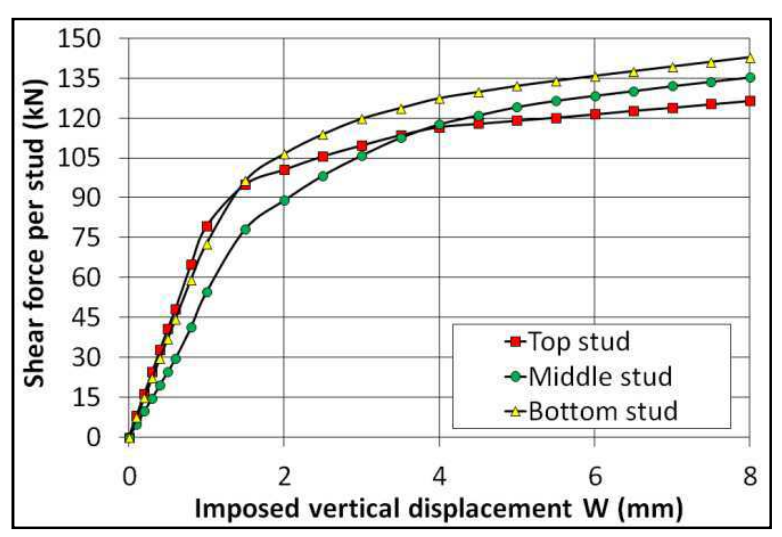

e $-H P C 1$.

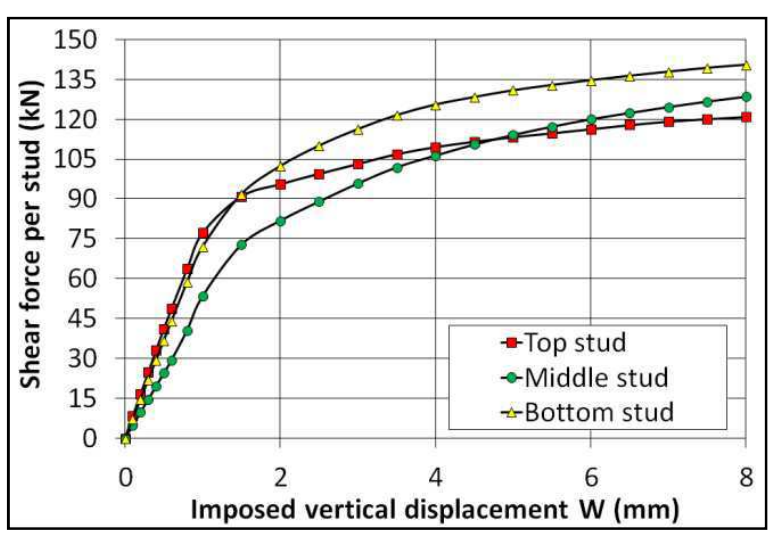

$$
\mathrm{g}-\mathrm{HPC} 3 \text {. }
$$

Figure 17 - Magnitude of shear forces.

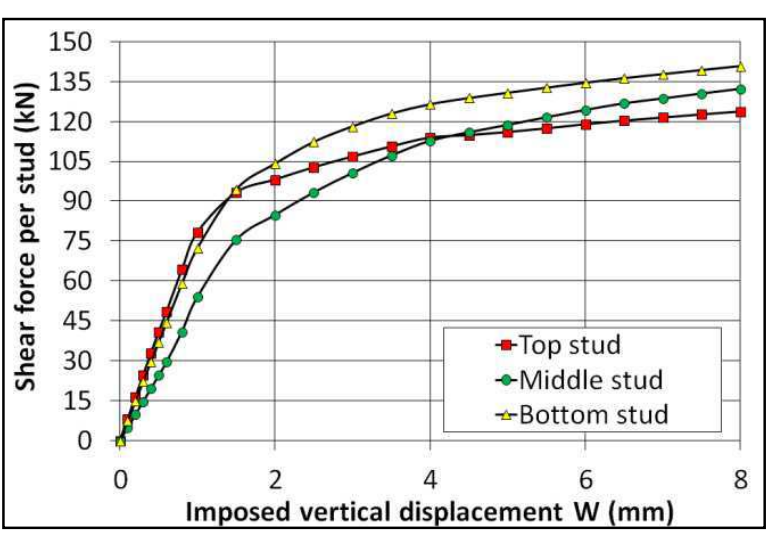

$\mathrm{f}-\mathrm{HPC} 2$.

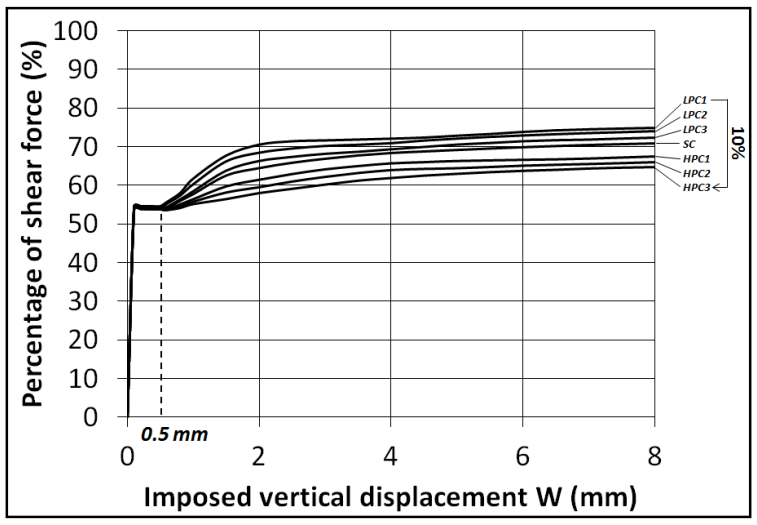

Figure 18 - Comparison between

different filling concrete performances.

In Figure 17, with the increase of the imposed vertical displacement $W$, one observes a relative decreasing of the shear force supported by the top stud-row (comparatively to both other stud-rows). An interpretation of the numerical data shows that this result is related to the loss of resistance of the top stud-row due to the tension force and the separation between the slab and the steel profile flange which increases for the most important imposed vertical displacement.

For a filling concrete with a resistance higher than NPC2 (or generally higher or equal to the slab concrete one), the bottom stud-row remains subjected to the higher shear force compared with other stud-rows.

In Figure 18 are plotted the percentages of the applied load supported by the studs as a shear force. Each curve corresponds to the sum of the top, the middle and the bottom shear forces. This sum is divided by the applied load that corresponds to the reaction $R$. Before $W=0.5$ $\mathrm{mm}$ all the curves are superimposed; this means that at the beginning of the push-out test, different filling concrete performances has no influence on the shear force supported by the studs. Over this "elastic range", the resistance of the studs decreases and the performance of the filling concrete begins to have an influence. It can be observed that the load supported by the studs is reduced by a most $10 \%$ when the filling concrete increases from NPC1 to HPC3. This result shows that the performance of the filling concrete has no significant influence on the shear force supported by the studs for these conditions of push-out test.

\subsection{Influence of the loading and boundary conditions}


Boundary conditions considered in precedent numerical simulations let all the nodes of the concrete panel free in horizontal X-direction (Figure 19.a). Precedent simulations showed that the percentage of the applied load supported by friction between materials has no important influence compared to the stud percentages. Sometimes, the support of the concrete is not free in X-direction, this condition could change the friction behaviour as-well-as the stud shear forces. In addition, possible compression applied on the right side of the concrete panel could also have an influence on the results. For the following numerical simulations, the filling concrete and the slab one are the same, 3 horizontal rows of studs are considered and the distance between each row of studs is equal to $4.26 \mathrm{~d}_{2}$. Different loading and boundary conditions will be applied to the concrete panel:

Case 1: Free for X-displacements (Figure 19.a).

Case 2: No X-displacements for the support (Figure 19.b).

Case 3: Free for X-displacements, no X-displacements on the right side of the concrete panel (Figure 19.c).

Case 4: Free for $\mathrm{X}$-displacements. Constant uniform compression $C=1 \mathrm{~mm}$ on the right side of the concrete panel (Figure 19.d).

Case 5: Free for X-displacements. Variable uniform compression on the right side of the concrete panel - Radial loading ( $W=0$ to $8 \mathrm{~mm}$ on steel section) and ( $V=0$ to $1 \mathrm{~mm}$ on concrete) - (Figure 19.e).

The stud shear force percentages for Case 1 to Case 5 are plotted in Figure 20 versus imposed vertical displacement $W$. It appears that the Case 1 leads to maximum force in the studs while Case 4 leads to the minimum especially for an imposed vertical displacement less than 0.5 $\mathrm{mm}$ (elastic range). At the beginning of the loading for an imposed vertical displacement less than $0.5 \mathrm{~mm}$ a difference increasing up to $25 \%$ is observed between the shear force percentages of Case 1 and Case 4 . Beyond $0.5 \mathrm{~mm}$, this difference decreases and similar values of percentages are observed for Cases 1 to 5. The difference of shear force supported by the studs does not exceed 6\%. Percentages of friction for each case are plotted in Figure 21. It is observed that for the Cases 1 and 2 (free outside of the concrete panel), the part of force supported by friction does not exceed 5\%. For the Cases 3 and 5, the percentage of friction appears more than $5 \%$ but less than $10 \%$. We remind that in the Case 5 , the specimen is loaded radially ( 0 to $8 \mathrm{~mm}$ vertical displacement for $W$ and 0 to $1 \mathrm{~mm}$ compression for $V$ ); the percentage of $10 \%$ depends clearly on the value of the outside face in compression $V$. The Case 4 is similar to Case 5 but the imposed horizontal displacement equal to $1 \mathrm{~mm}$ applied to the outside face of the slab remains constant (and not variable as in case 5). In this case, a peak of $30 \%$ friction percentage is observed at the beginning of the loading history and decreases suddenly when the exerted shear stress at the slab to the steel flange interface exceeds the friction shear strength due to initial slab compression. Afterwards the friction percentage remains constant and at least around $7 \%$. 


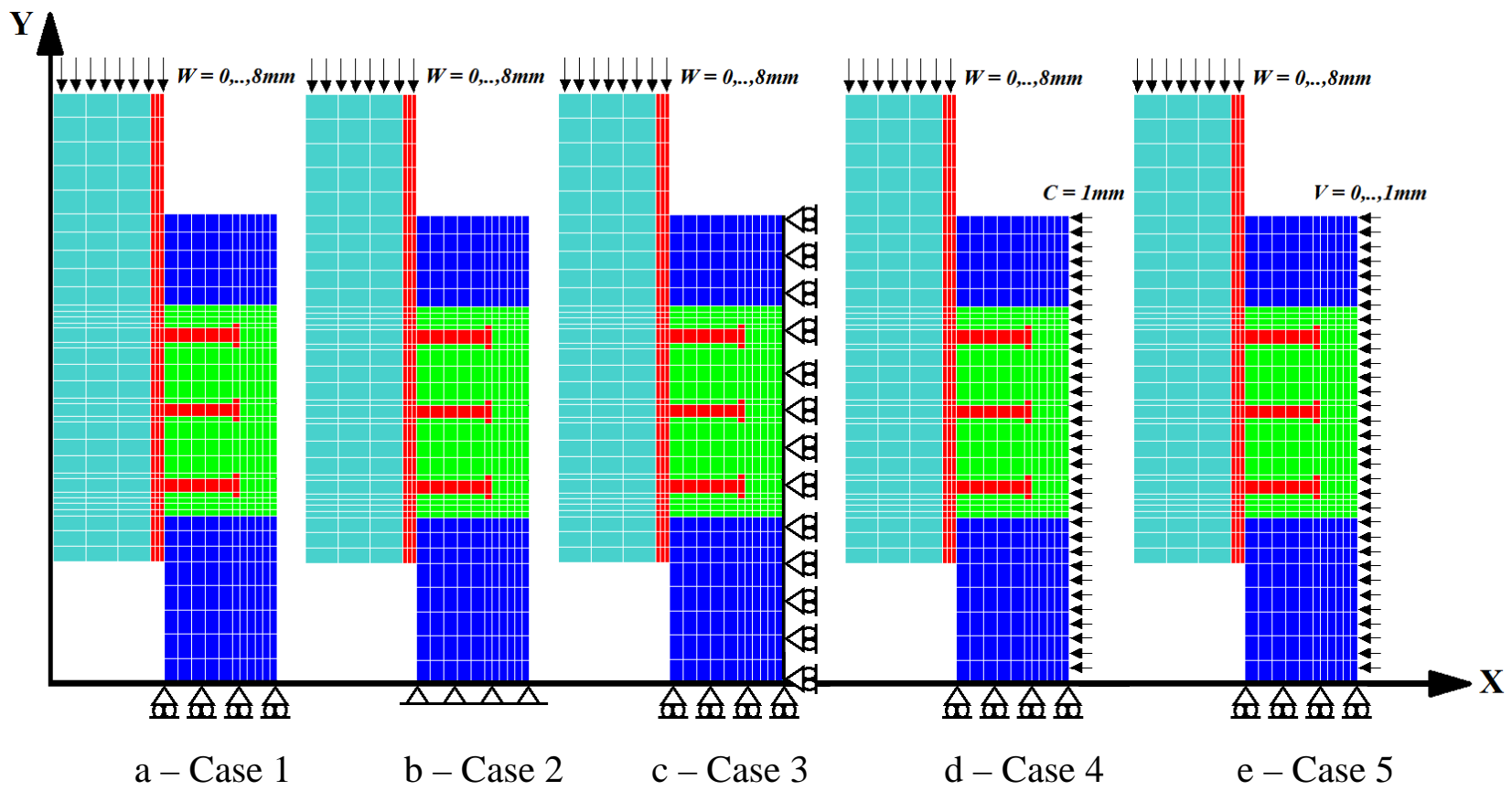

Figure 19 - Different boundary conditions of concrete panel and different loading histories.

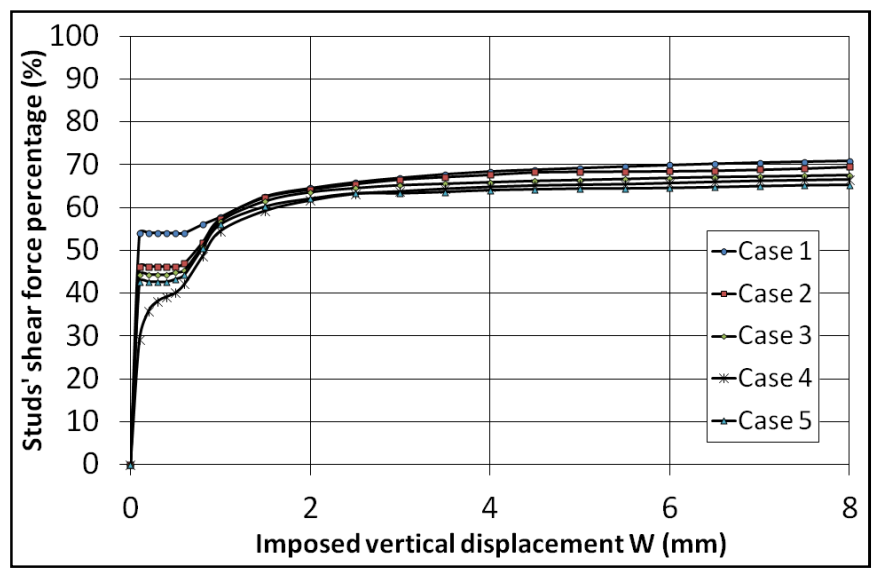

Figure 20 - Comparison of stud shear force percentages.

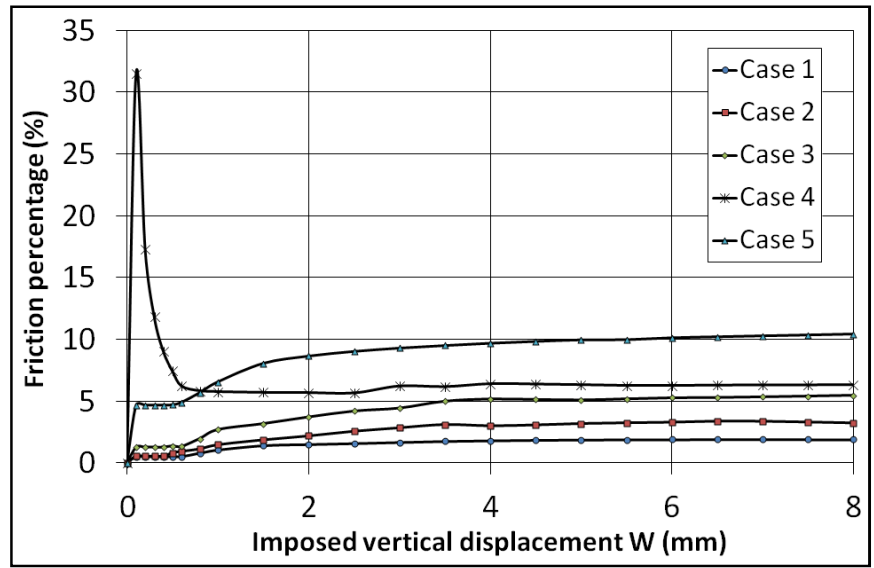

Figure 21 - Comparison of friction percentages.

It can be concluded that the compression added to the outside face of the concrete panel increases the shear force due to friction at the steel-concrete interface and decreases the shear force supported by the studs. The influence is more significant at the beginning of the test ( $W$ 
less than $1 \mathrm{~mm}$ ) and depends on the magnitude of the compressive load on the outside face of the concrete panel.

\section{CONCLUSION}

The results presented in this paper lead to following conclusions:

- The transfer of shear force throughout the specimen is now clearly identified for both cases (with or without friction). The real shear force transmitted at the base of the stud appears less than the magnitude of the applied load divided by the number of studs. Total shear force supported by the studs generally approaches $70 \%$ of the total applied load to the push-out test. It appears that the useful assumption made for the push-out test interpretation which considers that the shear force supported by each stud is equal to the applied load divided by the number of studs is conservative.

It could be interesting to compare numerical results with experimental ones. Unfortunately, experience has shown that it was totally unfeasible to instrument the base of a stud to get stress results; reasons are:

- Geometrical complexity of this zone.

- Contact and friction at the stud-concrete interface.

- Triaxiality of the stress state.

So, only a detailed numerical approach is able to provide information on the stress state in this area.

The numerical modeling makes appear a real interaction between the stud characteristics and the concrete strength as suggested by the first formulae proposed in [15] and more recently in [16].

- While the outside face of the concrete panel is free of loading, boundary conditions have no significant influence on the percentage of effort supported by friction (variation between $2 \%$ and $5 \%$ of the applied load).

- For different numbers of stud-rows (Figure 13) with imposed vertical displacement greater than $2 \mathrm{~mm}$, the percentage of shear force supported by each stud-row " $i$ " of a specimen with " $n$ " stud-rows is approximately equal to the percentage related to a model with only one studrow divided by " $n$ ".

- If the distance between the stud-rows increases, the shear force supported by each stud-row decreases and the concrete action on the studs increases.

- If the filling concrete performance increases, the shear force supported by the studs decreases and also the concrete action on the studs increases.

- If the outside face of the concrete panel is subjected to a variable compression (in addition to the imposed vertical displacement), the friction between the materials increases and the shear force supported by the studs decreases.

- For the Case 4, the outside face of the concrete panel is subjected to a constant compression (in addition to the imposed vertical displacement), an important peak of friction at the beginning of the test is observed and disappears over $2 \mathrm{~mm}$ of imposed vertical displacement.

\section{REFERENCES}


[1] Oguejiofor E. C. and Hosain M. U., Numerical analysis of push-out specimens with perfobond rib connectors. Computers \& Structures Volume 62, Issue 4, February 1997, Pages 617-624.

[2] Kim B., Wright H.D., Cairns R., The behaviour of through-deck welded shear connectors: an experimental and numerical study. Journal of Constructional Steel Research 57 (2001) 1359-1380.

[3] Johnson R.P., Oehlers D.J., Analysis and design for longitudinal shear in composite Tbeams. Proceedings of the Institution of Civil Engineers, Part 2 (1981) 989-1021.

[4] Jayas B.S., Hosain M.U., Behaviour of headed studs in composite beams: push-out tests. Canadian Journal of Civil Engineering 15 (1987) 240-253.

[5] LEBET J-P., Comportement des ponts mixtes acier-béton avec interaction partielle de la connexion et fissuration du béton. PHD thesis, Federal Polytechnic School, Lausanne, Suisserland (1987).

[6] ROIK K., HANSWILLE G., Zur Dauerfestigkeit von Koptbolzendübeln bei Verbundträgern. Bauingenieur 62 (1987) 273-385.

[7] HIRAGI H., MATSUI S., MUTO K., Development of Favourable Stud Shear Connectors to Flexible Composite Actions. Journal of Structural Engineering, 44A (1998) 1485-1496.

[8] Hosaka T., Hiragi H., Koeda Y., Tachibana T., Watanabe Y., An experimental Study on Characteristics of Shear Connectors in Composite Continuous Girders for Railway Bridges. Journal of Structural Engineering, 44A (1998) 1497-1504.

[9] Okada J., Lebet J.-P., Strength and behaviour of grouped stud connectors. Proceedings of 6th ASCCS Conference, Los Angeles, USA, vol. 1, March 2000, p. 321-328.

[10] Hanswille G. et al., Push-out Tests with Groups of Studs. ECSC Steel RTD Programme: Composite Bridge Design for Small and Medium Spans, Final report 7210-PR/113, Ch. 3 (2002) 3-1, 3-43.

[11] Lachal A., Aribert J-M. Demilecamps L., Shear behaviour of grouped stud connectors in precast slab: effects of filling material and recess arrangement. Proceedings of the 2nd International Symposium on Connections between Steel and Concrete, University of Stuttgart, Germany, vol. 2 (2007) 1233-1242.

[12] Guezouli S. and Lachal A., Numerical analysis of frictional contact effects in push-out tests. Journal of Structural Engineering Structures 40 (2012) 39-50.

[13] Qureshi J., Lam D. And Ye J., Effect of shear connector spacing and layout on the shear connector capacity in composite beams. Journal of Constructional Steel Research 67 (2011) 706-719. 
[14] EN 1994-1-1:2004: Eurocode 4: Design of composite and concrete structures - Part 1-1: General Rules and Rules for Buildings, European Committee for Standardization, 2004.

[15] Oehlers D. and Park S., Shear connectors in composite beams with longitudinally cracked slabs. Journal of Structural Engineering 118(8), (1992) 2004-2022.

[16] Xue W., Ding M., Wang H., Luo Z., Static behaviour and theoretical model of stud shear connectors. Journal of Bridge Engineering, ASCE, (2008) 623-634. 